\title{
Madagascar corals reveal a multidecadal signature of rainfall and river runoff since 1708
}

\author{
C. A. Grove ${ }^{1}$, J. Zinke ${ }^{1,2}$, F. Peeters ${ }^{3}$, W. Park ${ }^{4}$, T. Scheufen ${ }^{1,5, *}$, S. Kasper ${ }^{1}$, B. Randriamanantsoa ${ }^{6}$, \\ M. T. McCulloch ${ }^{7}$, and G.-J. A. Brummer ${ }^{1}$ \\ ${ }^{1}$ NIOZ Royal Netherlands Institute for Sea Research, Department of Marine Geology, P.O. Box 59, 1790 AB Den Burg, \\ Texel, the Netherlands \\ ${ }^{2}$ School of Earth and Environment, The University of Western Australia and the UWA Oceans Institute, 35 Stirling Highway, \\ Crawley WA 6009, Australia and the Australian Institute of Marine Science, 39 Fairway, Nedlands WA 6009, Australia \\ ${ }^{3}$ Vrije Universiteit Amsterdam, Faculty of Earth and Life Sciences, De Boelelaan 1105, \\ 1081 HV Amsterdam, the Netherlands \\ ${ }^{4}$ GEOMAR, Helmholtz-Zentrum für Ozeanforschung Kiel, Duesternbrooker Weg 20, 24105 Kiel, Germany \\ ${ }^{5}$ University of Amsterdam, Institute for Biodiversity and Ecosystem Dynamics (IBED), Nieuwe Achtergracht 127, \\ 1018 WS Amsterdam, the Netherlands \\ ${ }^{6}$ Wildlife Conservation Society (WCS), B.P. 8500 Soavimbahoaka, Antananarivo 101, Madagascar \\ ${ }^{7}$ The University of Western Australia and the UWA Oceans Institute, School of Earth and Environment, M004 and ARC \\ Centre of Excellence in Coral Studies, Crawley, Western Australia 6009, Australia \\ *now at: Unidad Académica de Sistemas Arrecifales, Instituto de Ciencias del Mar y Limnología, \\ Universidad Nacional Autónoma de México, Apdo. Postal 1152, Cancún, Quintana Roo 77500, Mexico
}

Correspondence to: C. A. Grove (craig.grove@ nioz.nl)

Received: 15 February 2012 - Published in Clim. Past Discuss.: 12 March 2012

Revised: 5 February 2013 - Accepted: 6 March 2013 - Published: 13 March 2013

\begin{abstract}
Pacific Ocean sea surface temperatures (SST) influence rainfall variability on multidecadal and interdecadal timescales in concert with the Pacific Decadal Oscillation (PDO) and Interdecadal Pacific Oscillation (IPO). Rainfall variations in locations such as Australia and North America are therefore linked to phase changes in the PDO. Furthermore, studies have suggested teleconnections exist between the western Indian Ocean and Pacific Decadal Variability (PDV), similar to those observed on interannual timescales related to the El Niño Southern Oscillation (ENSO). However, as instrumental records of rainfall are too short and sparse to confidently assess multidecadal climatic teleconnections, here we present four coral climate archives from Madagascar spanning up to the past $300 \mathrm{yr}$ (1708-2008) to assess such decadal variability. Using spectral luminescence scanning to reconstruct past changes in river runoff, we identify significant multidecadal and interdecadal frequencies in the coral records, which before 1900 are coherent with Asian-based PDO reconstructions. This
\end{abstract}

multidecadal relationship with the Asian-based PDO reconstructions points to an unidentified teleconnection mechanism that affects Madagascar rainfall/runoff, most likely triggered by multidecadal changes in North Pacific SST, influencing the Asian Monsoon circulation. In the 20th century we decouple human deforestation effects from rainfallinduced soil erosion by pairing luminescence with coral geochemistry. Positive PDO phases are associated with increased Indian Ocean temperatures and runoff/rainfall in eastern Madagascar, while precipitation in southern Africa and eastern Australia declines. Consequently, the negative PDO phase that started in 1998 may contribute to reduced rainfall over eastern Madagascar and increased precipitation in southern Africa and eastern Australia. We conclude that multidecadal rainfall variability in Madagascar and the western Indian Ocean needs to be taken into account when considering water resource management under a future warming climate. 


\section{Introduction}

Tropical Indian Ocean warming in the 20th century has accelerated since the late 1970s, affecting rainfall patterns and intensity across much of the western Indian Ocean and adjacent landmasses of eastern and southern Africa (Richard et al., 2000; Funk et al., 2008). As both these regions heavily depend on regular rainfall for food production and ecosystem sustainability (Fleitmann et al., 2007), the uncertainty in the rainfall response to accelerated warming of the Indian Ocean is a serious socioeconomic issue of global importance (Funk et al., 2008). To fully assess this response it is necessary to identify the long-term natural rainfall patterns, yet we currently lack an understanding of the major drivers of natural decadal rainfall variability in the Indian Ocean and the regional synergy with global warming (Cane, 2010). Some evidences indicate that decadal and interdecadal South African rainfall is associated with the El Niño-Southern Oscillation (ENSO) due to the shifting tropical temperature troughs in response to large-scale changes in Indo-Pacific sea surface temperature (SST) and sea level pressure (SLP) (Reason and Rouault, 2002). Since rainfall patterns are sensitive to SST change, which includes both natural internal variability and anthropogenic forcing, here we investigate natural multidecadal and interdecadal modulation of Indian Ocean rainfall/river runoff in response to Indo-Pacific SST variability.

The Pacific Decadal Oscillation (PDO) is a major mode of climate variability (Mantua et al., 1997). Positive PDO phases are characterised by lower than average SST in the central midlatitude Pacific and warm anomalies along the northern and eastern margins, and south of $30^{\circ} \mathrm{N}$. The PDO is remotely forced from the Tropics in part (Schneider and Cornuelle, 2005), and responsible for strong multidecadal (50-70 yr) (Minobe, 1997) and interdecadal Pacific oscillations in SST (IPO; 17-28 yr) (Meehl and Hu, 2006). The PDO is considered as the leading mode of North Pacific SST variability, defined by instrumental data for the past $120 \mathrm{yr}$ (Mantua et al., 1997), and recognised in extended proxy time series, e.g. tree ring records of rainfall in NE Asia (D'Arrigo and Wilson, 2006).

The IPO is often referred to as a Pacific-wide manifestation of the PDO (Power et al., 1999). The IPO is known to modulate ENSO over eastern Australia, whereby negative phases increase the intensity and frequency of wet La Niña events (Power et al., 1999; Kiem et al., 2003; Kiem and Franks, 2004; Verdon et al., 2004). As the PDO and IPO indices highly correlate (correlation $=0.86$ ), Henley et al. (2011) refer to them collectively as the IPO-PDO phenomena. However, significant differences exist between published IPO-PDO reconstructions that extend beyond the 1900s (Biondi et al., 2001; D'Arrigo et al., 2001; Gedalof and Smith, 2001; MacDonald and Case, 2005; D'Arrigo and Wilson, 2006; Shen et al., 2006; Henley et al., 2011). Henley et al. (2011) suggest this is because of uncertainties associated with the paleo-data itself and its interpretation, nonlinearities and errors in the original physical data analysis, nonstationarity of the proxy/climate relationship, and/or the different levels of explained variance between the various proxies at various locations.

Given the significant differences between published IPOPDO reconstructions, the persistence of the PDO pre-1900 has been debated (Di Lorenzo et al., 2008; Henley et al., 2011). It has been suggested that no well-defined coupled ocean-atmosphere "mode" of variability exists in the Pacific on decadal to interdecadal timescales, since paleoclimate records conflict and instrumental records are too short to provide a robust assessment (Biondi et al., 2001; Gedalof et al., 2002; Schneider and Cornuelle, 2005). Schneider and Cornuelle (2005) suggest that the PDO is not itself a mode of variability but is a blend of three phenomena. Nevertheless, the North Pacific and the equatorial Pacific do vary on interdecadal to multidecadal timescales, and the manifestation of this Pacific Decadal Variability (PDV) and its influence on surrounding regions needs to be better understood (Schneider and Cornuelle, 2005).

Mounting evidence indicates that the PDO or PDV has teleconnections extending to the Indian Ocean (Cole et al., 2000; Crueger et al., 2009). The positive PDO phase corresponds to warm Indian Ocean SST anomalies (Deser et al., 2004), thought to exceed SST anomalies associated with ENSO (Krishnan and Sugi, 2003), particularly in the southwestern Indian Ocean (Fig. 2a) (Meehl and Hu, 2006). While it is evident that changing rainfall patterns over Australia (Power et al., 1999; Arblaster et al., 2002; Verdon et al., 2004; Meinke et al., 2005) and North America (Mantua et al., 1997; Minobe, 1997) respond to the PDO, links to rainfall in southeastern Africa and the western Indian Ocean have only been suggested (Deser et al., 2004; Zinke et al., 2008). In this study we investigate the primary modulators of Madagascar (SW Indian Ocean) rainfall on multidecadal and interdecadal timescales by applying coral cores.

Massive corals such as Porites spp. offer century-long geological archives locked within their skeletons. Further, corals that reside close to river systems can potentially record temporal variability in soil and sediment erosion, resulting in highly resolved and continuous proxy records of changing terrestrial impacts on the coastal ocean (McCulloch et al., 2003; Fleitmann et al., 2007; Lough, 2007, 2011a) (Appendix A). Luminescence in banded corals is indicative of past humic acid runoff from river discharge (Isdale, 1984; Susic and Boto, 1989; Susic et al., 1991; Matthews et al., 1996; Isdale et al., 1998; Wild et al., 2000; Grove et al., 2010, 2012) (Appendix A), while skeletal $\mathrm{Ba} / \mathrm{Ca}$ as an indicator for past suspended sediment runoff (Alibert and McCulloch, 1997; McCulloch et al., 2003; Sinclair and McCulloch, 2004; Maina et al., 2012). Here we present up to $300 \mathrm{yr}$ of monthly resolved proxy records of soil erosion from four giant Porites spp. colonies growing in two coastal marine catchments of eastern Madagascar (Fig. 1) (Appendix A). Significant temporal correlations of $\mathrm{Ba} / \mathrm{Ca}$ 


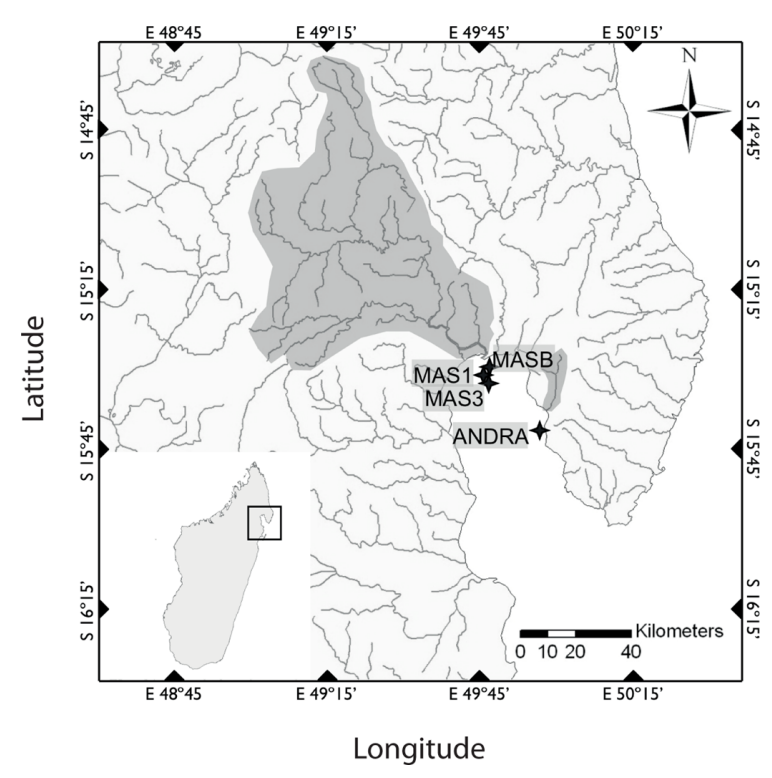

Fig. 1. Map of the region where coral cores MAS1, MAS3, MASB and ANDRA were drilled. Coral locations (stars) and their corresponding rivers and watersheds (grey shaded areas) are marked accordingly in Antongil Bay. The largest river is the Antainambalana, influencing MAS1, MAS3 and MASB. ANDRA is also influenced by a separate river, the Ambanizana, flowing south westward into the bay.

with luminescence have previously been observed in studies using the same coral cores analysed here (Grove et al., 2010, 2012). As well as the runoff proxies, $\mathrm{Sr} / \mathrm{Ca}$ and $\mathrm{Mn} / \mathrm{Ca}$ data are presented in this study. Coral skeletal $\mathrm{Sr} / \mathrm{Ca}$ is an indicator of SST (Beck et al., 1992; Corrège, 2006; Alibert and McCulloch, 1997) and $\mathrm{Mn} / \mathrm{Ca}$ is used as an indirect indicator of ash fallout from slash-and-burn deforestation (Abram et al., 2003).

\section{Materials and methods}

\subsection{Research area and climate setting}

Coral cores were taken from Antongil Bay in NE Madagascar, which is surrounded by one of the country's largest remaining rainforests (Birkinshaw and Randrianjanahary, 2007). Air temperature and rainfall in Antongil Bay was monitored for the period 1992 to 1996 (Kremen, 2003). Antongil Bay is characterised by an August-December cold-dry season and a January-July warm-wet season. Air temperatures peak in December and January and are lowest between July and September. Highest rainfall occurs between January and April, while lowest rainfall occurs between September and November (Kremen, 2003; Jury et al., 1995). The annual average precipitation at Andranobe (coral site ANDRA) was $6049 \mathrm{~mm}(1 \mathrm{SD}=979 \mathrm{~mm})$ between 1992 and 1996. Highest river discharge occurs between January and April, reaching lows in October and November (Gerten et al., 2008).

\subsection{Coral sampling and analysis}

Three live corals MAS1, MAS3 and ANDRA were drilled in March 2007 from Antongil Bay, NE Madagascar, dating back to 1904, 1880 and 1914, respectively (Figs. 1 and S1; Table S1 in the Supplement) (Grove et al., 2010). Another live coral, MASB $\left(15^{\circ} 30.566 \mathrm{~S} ; 49^{\circ} 45.437 \mathrm{E}\right)$, was drilled in October 2008, dating back to 1708 (Figs. 1 and S2; Table S1 in the Supplement). Three of the corals used for this study, MAS1, MAS3 and MASB are directly influenced by a major river draining into the Bay, named Antainambalana (Fig. 1) (Grove et al., 2012). Its source lies $1450 \mathrm{~m}$ above sea level and its watershed covers an estimated $4000 \mathrm{~km}^{2}$. As well as being influenced by the Antainambalana, a fourth coral, ANDRA, is located $30 \mathrm{~km}$ south of MAS1/3/B, and is located $7 \mathrm{~km}$ from a much smaller river called the Ambanizana, which has a watershed of $160 \mathrm{~km}^{2}$ (Grove et al., 2012).

All cores were sectioned into $7 \mathrm{~mm}$ slabs, cleaned with sodium hypochlorite $(\mathrm{NaOCl}, 10-13 \%$ reactive chloride; Sigma-Aldrich Company) for $24 \mathrm{~h}$ to remove residual organics that would quench luminescence (Nagtegaal et al., 2012), and subsequently scanned under UV light to measure continuous spectral luminescence ratios (G/B; Green/Blue) (Grove et al., 2010). MASB was cleaned for a further $24 \mathrm{~h}$ with $\mathrm{NaOCl}$ to remove resistant organic contaminants that remained after a single cleaning step. Corals were dated by counting density and luminescent bands down core (Hendy et al., 2003; Grove et al., 2010). Annual growth bands were visualised by X-radiograph-positive prints, and the growth axis of the coral slab was defined as the line normal to these bands (Helmle et al., 2011). All four corals used in this study displayed wide luminescent bands (Figs. S1 and S2 in the Supplement), reflecting the broad seasonal cycle in both precipitation and river discharge that are characteristic of the study site (Grove et al., 2012; Maina et al., 2012). Age models for all corals are based on seasonal cycles in luminescence (G/B) (Figs. S1 and S2 in the Supplement). All coral age models for luminescence $(\mathrm{G} / \mathrm{B})$ data were based on $\mathrm{G} / \mathrm{B}$ anchor points that correspond to October, the lowest (driest) value in any given year (Grove et al., 2010). For each high resolution $\mathrm{G} / \mathrm{B}$ data point we assigned a date between the October anchor points using AnalySeries 2.0 (Paillard et al., 1996). The luminescence (G/B) data were then converted to a monthly timescale (12 samples per year) using a further interpolation step between the October minima values (Paillard et al., 1996), the driest month in the Antongil Bay region (Kremen, 2003; Grove et al., 2010).

Spectral luminescence scanning (SLS) was performed on bleached coral slabs using a line-scan camera fitted with a Dichroic beam splitter prism, separating light emission intensities into three spectral ranges; blue (B), green $(G)$ and red (R) (Grove et al., 2010). Since the spectral emissions of humic acids $(G)$ are slightly longer than aragonite (B), spectral $\mathrm{G} / \mathrm{B}$ ratios reflect the changing humic acid/aragonite ratios 
within the coral skeleton (Grove et al., 2010) (Appendix A). The precision of the $\mathrm{G} / \mathrm{B}$ ratio was obtained from the top $10.5 \mathrm{~cm}$-long section of the ANDRA coral core by taking replicate measurements (5-fold) and calculating the standard deviation as a proportion of the mean G/B value. The median error was $1.56 \%(-0.12 /+4.54)$, which translates to an absolute median error of $0.015(-0.001 /+0.043)$. Luminescence imaging of the MAS3 core revealed some dark stains in the older sections of the core, therefore as a precaution luminescence data starts in 1930. A composite G/B record was created by normalising the 4 coral cores by removing a common period (1961-1990) and averaging the records together. This reduces the local signals associated with each core, allowing us to assess the regional response to runoff. The composite $\mathrm{G} / \mathrm{B}$ record was used when applying record segmentation analysis (Supplement) and assessing relationships with observational climate data (Appendix A).

Laser-Ablation Inductively Coupled Plasma Mass Spectrometry (Laser-Ablation ICP-MS) profiles were taken to analyse the trace element ratios of $\mathrm{Sr} / \mathrm{Ca}, \mathrm{Ba} / \mathrm{Ca}$ and $\mathrm{Mn} / \mathrm{Ca}$ at $40 \mu \mathrm{m}$ intervals on the coral cores MAS1 and MAS3 at ANU Canberra (Sinclair et al., 1998; Fallon et al., 2002). Data were first smoothed using a 10 point running mean to reduce the influence of outliers, followed by a 10 point stepped mean to reduce data volume. This procedure reduced the sampling resolution from $40 \mu \mathrm{m}$ to about $200 \mu \mathrm{m}$ per sample point. At an average growth rate of about $1 \mathrm{~cm}$ per year for Porites spp., this resulted in a sampling resolution of 50 samples per year. To determine accuracy, a NIST 614 glass standard and a pressed coral standard were used (Fallon et al., 1999, 2002). Daily and long-term (5 month) reproducibility was monitored by repeated measurements of the pressed coral standard and an in-house coralline sponge standard (Fallon et al., 1999). The daily and long-term reproducibility was $1.6 \%$ and $3.3 \%$, respectively. The analytical internal precision for $\mathrm{Ba} / \mathrm{Ca}$ was $4.3 \%$ RSD (Fallon et al., 1999). Further details on the methodology and standards are available in Fallon et al. (1999, 2002).

Laser-Ablation ICP-MS profiles cover the entire age of MAS1 (1904-2006) and since 1935 for MAS3 (1935-2006) (Table S1). Age models for $\mathrm{Sr} / \mathrm{Ca}, \mathrm{Mn} / \mathrm{Ca}$ and $\mathrm{Ba} / \mathrm{Ca}$ for all corals are based on $\mathrm{Ba} / \mathrm{Ca}$ anchor points that correspond to October, the lowest (driest) value in any given year (Kremen, 2003; Grove et al., 2010, 2012). In a first interpolation step (based on the 50 samples per year resolution) we assigned a date to each data point using AnalySeries 2.0 (Paillard et al., 1996). Subsequently, in a second step, we interpolated the high resolution data to a monthly timescale.

In this study we assess coral proxy records together with the SST and rainfall data available. For SST data we used gridded ERSST (v.3) (Smith et al., 2008). For rainfall we used data from the Climate Research Unit (CRU) at the University of East Anglia (CRU TS3) (Mitchell and Jones, 2005), CMAP (Xie and Arkin, 1997), NCEP/NCAR reanalysis (Kalnay et al., 1996), CAMS_OPI (Janowiak and Xie,
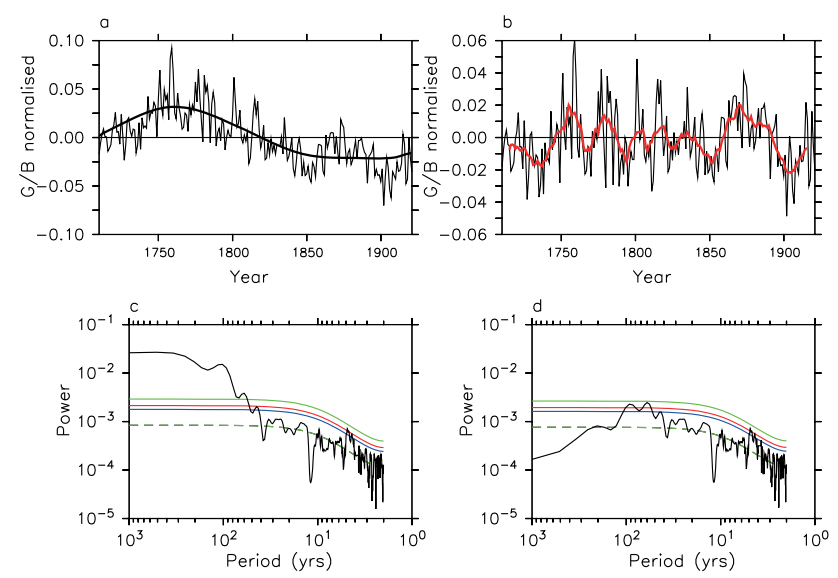

Fig. 2. Time series of annual mean G/B anomalies of the MASB data (a) for 1709-1920 (thin line). The thick curve represents the reconstructed long-term variation of MASB from the first two SSA (Singular Spectrum Analysis) modes that represent $55 \%$ of the total MASB variability. Time series of the MASB data (b) in which the long-term variation in (a) is subtracted. An $11 \mathrm{yr}$ running average (red) is applied to the time series in order to visualise the interdecadal and multidecadal changes. The spectrum of (a) and (b) are shown in (c) and (d), respectively. Confidence levels are indicated with green $(99 \%)$, red $(95 \%)$, blue $(90 \%)$ and green dashed (median) lines, respectively.

1999) and the longest continuous precipitation record from Madagascar (Antananarivo; WMO station 67083). Singular Spectrum (SSA) (Ghil et al., 2002) and coherence analysis, cross-wavelet analysis (Grinsted et al., 2004) and record segmentation were the primary statistical methods applied to time series presented here.

\section{Results and discussion}

\subsection{River runoff reconstructions using coral luminescence}

We measured the $\mathrm{G} / \mathrm{B}$ ratio in corals to determine seasonally resolved soil-derived humic acid runoff resulting from hinterland rainfall (Grove et al., 2010) (Appendix A). A spatial assessment study of coral cores from Antongil bay revealed that absolute coral G/B values and seasonality are related to discharge rates of individual rivers (Grove et al., 2012). All coral records used in this study shared a significant amount of variance on annual timescales, with the only exception being MAS3 G/B with MASB G/B (Table 1; Fig. A1). When correlating the four coral MAS G/B composite record with different rainfall datasets, clear significant positive relationships are observed in the Antongil bay region (Fig. A2). Although different rainfall datasets show a varying degree of correlation with G/B (Fig. A2), all are significant, with the highest relationship being with NCEP/NCAR reanalysis (Kalnay et al., 1996) $(R=0.421 ; P=0.0014 ; N=50)$. 
Table 1. Correlations of annual average $\mathrm{G} / \mathrm{B}$ and $\mathrm{Ba} / \mathrm{Ca}$ between coral records. Correlations are calculated using the maximum number $(N)$ of years shared between corals. Individual G/B records are graphically shown in Fig. A1.

\begin{tabular}{lll}
\hline Coral Cores & $\mathrm{G} / \mathrm{B}$ & $\mathrm{Ba} / \mathrm{Ca}$ \\
\hline MAS1 vs. MAS3 & $R=0.430 ; P<0.001 ; N=71$ & $R=0.656 ; P<0.001 ; N=71$ \\
MAS1 vs. ANDRA & $R=0.627 ; P<0.001 ; N=92$ & \\
MAS1 vs. MASB & $R=0.482 ; P<0.001 ; N=102$ & \\
MAS3 vs. ANDRA & $R=0.568 ; P<0.001 ; N=71$ & \\
MAS3 vs. MASB & $R=0.129 ; \mathrm{P}=0.284 ; N=71$ & \\
ANDRA vs. MASB & $R=0.433 ; P<0.001 ; N=92$ & \\
\hline
\end{tabular}

A recent hydrological model-coral proxy comparison study for the Antainambalana river watershed revealed that rainfall, river discharge and sediment runoff explained the variance in coral proxies of terrestrial river runoff (Maina et al., 2012). However, correlations of MAS1 G/B with a regional rainfall dataset located $200 \mathrm{~km}$ from the coral site showed a low yet statistically significant relationship (Grove et al., 2010). We suggest that this relationship was dampened by the well documented slash-and-burn deforestation period NE Madagascar experienced in the mid-century during the social uprising (Green and Sussman, 1990; Harper et al., 2007). As G/B is an indicator of humic acid runoff and not rainfall, G/B variability can also be related to deforestation induced erosion.

\subsection{Pre-anthropogenic climatic modulation of runoff}

We investigated pre-anthropogenic climatic modulation of humic acid runoff by analysing the $300 \mathrm{yr}$ long coral core record, dating from November 1708 to November 2008 (MASB; Fig. 1). To eliminate any potential anthropogenic impact on past humic acid runoff we first focused on the period 1709-1920 (Fig. 2). Annual mean time series of the G/B data (Fig. 2a) and its spectrum (Fig. 2c) identified frequencies at centennial, multidecadal and interdecadal timescales. In particular, the centennial and multidecadal spectral peaks were above the $95 \%$ confidence level. We next removed the long-term centennial variability from the time series to focus on shorter timescales, i.e. multidecadal and interdecadal, which are the subjects of the present study. The long centennial variability was reconstructed using the first and second mode of the singular spectrum analysis (SSA), as shown by the low-frequency solid line in Fig. 2a. The residual time series (Fig. 2b) showed no trend or long-term centennial variability, with its periodicity concentrated in the 50-70 yr and 20-30 yr bands (Fig. 2d), similar to the dominant periodicity associated with Pacific decadal variability (PDO and IPO), known to influence Indian Ocean SST (Krishnan and Sugi, 2003; Cole et al., 2000; Deser et al., 2004; Crueger et al., 2009). The multidecadal peak of the residual time series (Fig. 2b) remained above the $95 \%$ confidence level with the removal of the long-term centennial variability. However, the interdecadal (20-30 yr bands) spectral peak remained below the $95 \%$ confidence level.

The multidecadal and interdecadal variability in MASB G/B between 1709 and 1920 explained $7 \%$ and $4 \%$ (total of $11 \%$ ) of the total variability, respectively. This was considerably lower than the long-term centennial variability of $55 \%$. When the centennial variability was subtracted from the record (Fig. 2), the 50-70 yr band explained $18 \%$ of the residual time series variability (Fig. 2b) and the 20-30 yr band $9 \%$ (total of $27 \%$ ). As the IPO-PDO is known to influence Indian Ocean SST (Krishnan and Sugi, 2003; Cole et al., 2000; Deser et al., 2004; Crueger et al., 2009), we investigated the relationship of MASB G/B with the IPO-PDO on multidecadal and interdecadal timescales. Since the instrumental PDO index (Mantua et al., 1997) only dates back to 1880, the 1709-1920 MASB G/B time series was compared to a number of PDO reconstructions to further investigate decadal variability in runoff (Figs. 3 and S3). In agreement with Shen et al. (2006) and Henley et al. (2011), we observed a large spread between the individual PDO reconstructions. Some indicated stronger power related to the interdecadal component of the PDO (IPO), and others the multidecadal component (Fig. S3).

For the MASB G/B time series, we observed most coherence with the PDO reconstructions from Asia (D'Arrigo and Wilson, 2006; Shen et al., 2006), both on interdecadal and multidecadal timescales (Figs. 3, 4 and S3). The dominant spectral peak of the D'Arrigo and Wilson (2006) index was between 20-40 yr, yet the Shen et al. (2006) index was between 50-70 yr (Fig. S3). The MASB G/B time series also showed similarities with the Mann et al. (2009) SST reconstruction and with the combined PDO reconstruction of Henley et al. (2011) (Figs. 3 and S3). When considering the North American based PDO reconstructions specifically (Biondi et al., 2001; D’Arrigo et al., 2001; Gedalof and Smith, 2001; MacDonald and Case, 2005), the Madagascar runoff record showed an anti-phase relationship or a delayed response between 1709 and 1850 (Figs. 3 and S3). This is particularly highlighted in the MacDonald and Case (2005) PDO reconstruction, where although strong multidecadal and interdecadal coherence is observed, the two records clearly show an opposite or delayed response between 1709 and 

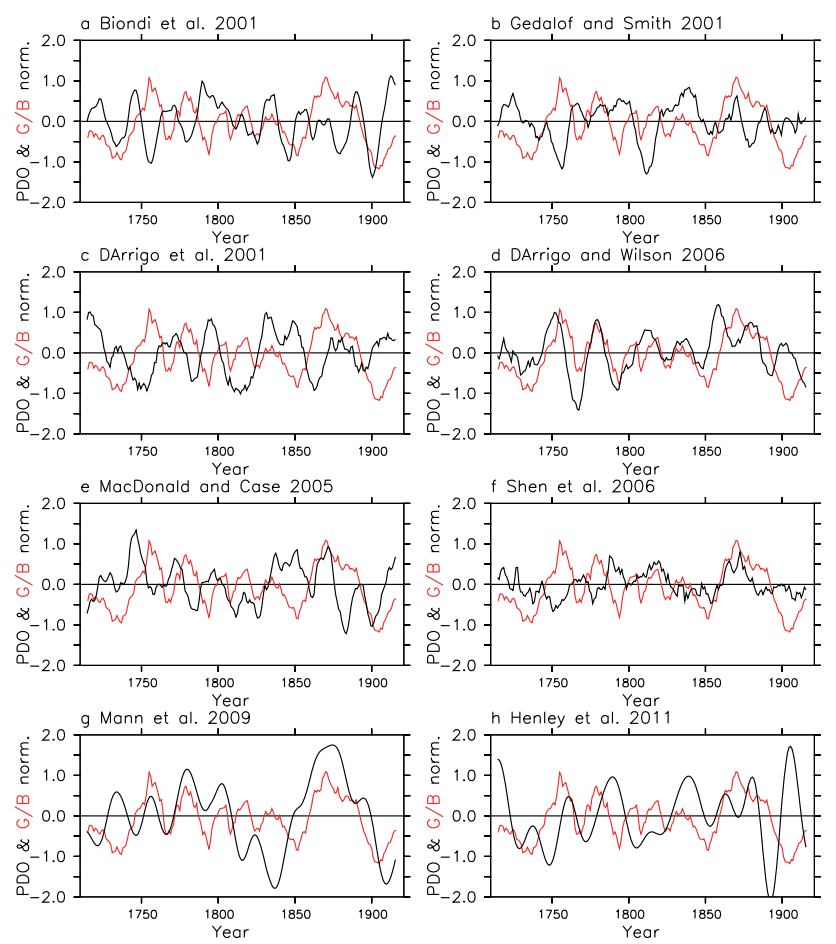

Fig. 3. Comparison of the higher frequency MASB G/B data (as represented in Fig. 2b) for 1709-1920 (a-h; red line), with a variety of reconstructed PDO indices (black line), including the (a) Biondi et al. (2001), (b) Gedalof and Smith (2001), (c) D'Arrigo et al. (2001), (d) D'Arrigo and Wilson (2006), (e) MacDonald and Case (2005), (f) Shen et al. (2006), (g) Mann et al. (2009) and (h) Henley et al. (2011) records. The MASB G/B data were standardised and all reconstructed PDO time series were detrended and subsequently standardised prior to the analysis. An $11 \mathrm{yr}$ running average was applied to both the MASB G/B and PDO time series in order to visualise the interdecadal and multidecadal changes.

1850 (Figs. 3 and S3). This is also apparent with the Biondi et al. (2001) record, yet not as pronounced (Fig. 3 and S3).

To investigate time-dependent frequency relationships between MASB G/B and the reconstructed PDO indices we applied a wavelet coherence analysis (Fig. 4). Similar to the visual time series comparison, clear multidecadal and interdecadal relationships were observed between MASB G/B and the Asian PDO reconstructions (Fig. 4d, f; D'Arrigo and Wilson, 2006; Shen et al., 2006), whereby an in-phase relationship existed on multidecadal timescales. On interdecadal timescales, an in-phase relationship was observed between MASB G/B and the D'Arrigo and Wilson (2006) PDO reconstruction, while the Shen et al. (2006) reconstruction indicated an anti-phase relationship in the early part of the record (1709-1800). Other PDO reconstructions showed rather patchy coherence, with the exception of the MacDonald and Case (2005) index, which again indicated a delayed response on multidecadal timescales, such that the PDO lead the MASB G/B record. However, it should be
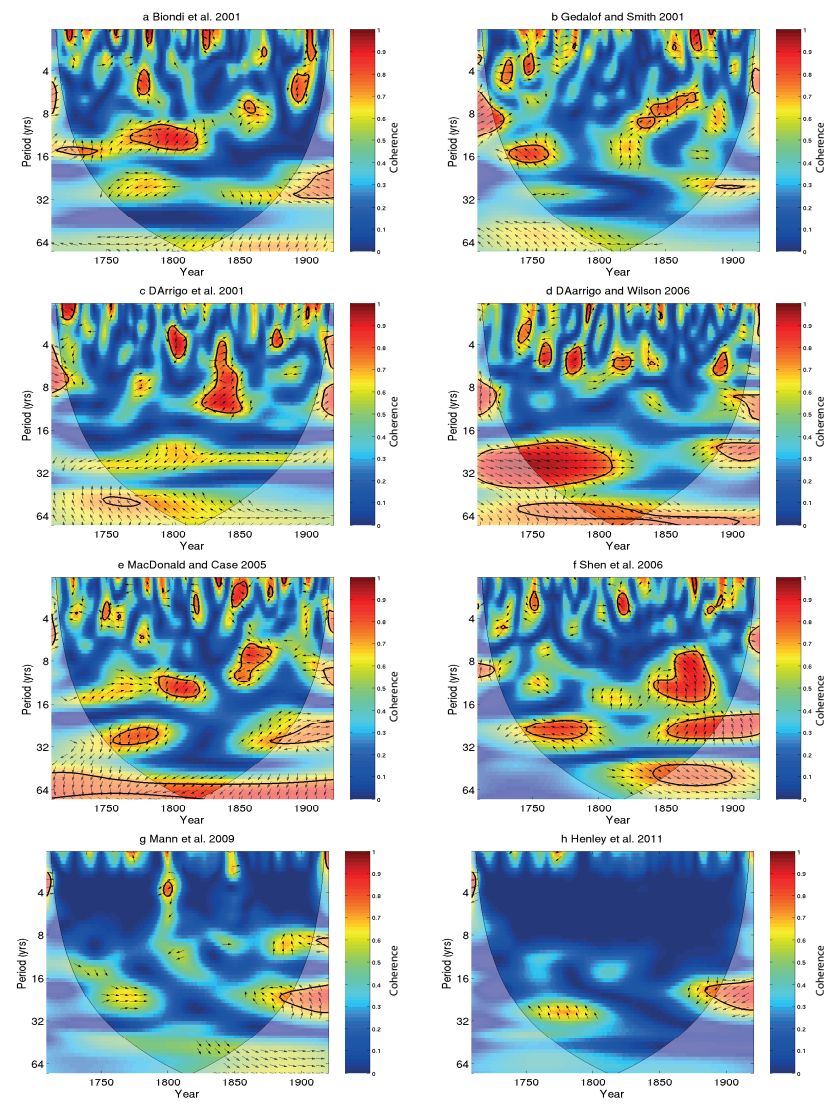

Fig. 4. Cross-wavelet coherence analysis of MASB G/B 1709-1920 data (as represented in Fig. 2b, with the centennial scale variance removed.) with a variety of reconstructed PDO indices, including the (a) Biondi et al. (2001), (b) Gedalof and Smith (2001), (c) D' Arrigo et al. (2001), (d) D'Arrigo and Wilson (2006), (e) MacDonald and Case (2005), (f) Shen et al. (2006), (g) Mann et al. (2009) and (h) Henley et al. (2011) records, as shown in Fig. 3. The $5 \%$ significance level against red noise is shown as a thick contour. Phases are indicated as arrows, where directing right represents an in phase, and a clockwise direction indicates a lead of the PDO.

noted that such timescales are still too short to fully resolve coherence at multidecadal timescales, and that wavelet coherence should be interpreted carefully when hypothesising exact phase relationships. Therefore, to validate the relationship between the PDO and MASB G/B we applied another approach by means of filtering the time series.

As the clearest in-phase coherence of the coral runoff record was observed with both the NE Asia tree ring based PDO reconstruction (D'Arrigo and Wilson, 2006) and the eastern China flood/drought PDO reconstruction (Shen et al., 2006) (Fig. 5a, grey boxes), we focus on these time series for the remainder of this study. We applied a 50-70 yr band pass filter to the data as this is the defined frequency of the PDO (Minobe, 1997) (Fig. 5c). The D'Arrigo and Wilson (2006) record showed near identical changes in phase and timing with the coral runoff record for over two centuries in the 

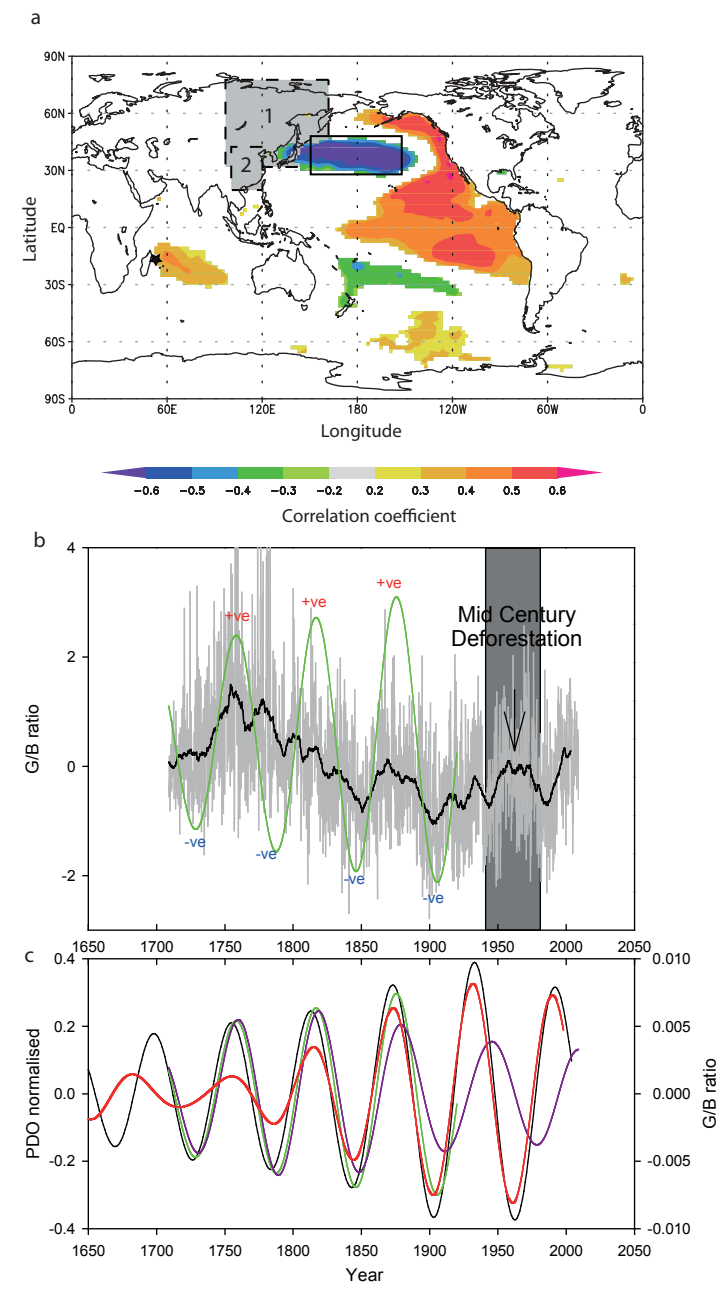

Fig. 5. Typical positive PDO phase (a) indicated by global SST anomalies. Yearly (May-April) global SST (ERSSTv.3) correlate with the PDO index (Mantua et al., 1997), with positive and negative anomalies at $>95 \%$ significance level indicated by colours. The black outlined box on the map (a) shows the strong negative anomalies of the central North Pacific during a positive PDO phase. The grey shaded box 1 (a) indicates the region used to compile the NE Asian 500 yr reconstructed tree ring PDO index (D'Arrigo and Wilson, 2006), and box 2 the region used to compile the eastern China $530 \mathrm{yr}$ reconstructed drought/flood PDO index (Shen et al., 2006). Monthly MASB G/B (grey line) and the 11 yr running mean (black line) are shown (b) together with the 50-70 yr band passfiltered $(0.017 \pm 0.003)$ data up to 1920 (green). Peaks and troughs (b) represent multidecadal positive (red) and negative (blue) runoff anomalies. The same 50-70 yr band pass filter (c) is also applied to the NE Asia PDO reconstruction (black), the eastern China PDO reconstruction (red), MASB G/B 1708-2008 (purple) and MASB G/B 1708-1920 (green). Both PDO reconstructions are coherent with the MASB G/B 1708-1920 time series (c), therefore positive PDO phases are associated with positive runoff anomalies. When considering the total MASB G/B time series (1708-2008), the relationship with both PDO reconstructions breaks down post 1920. multidecadal frequency band (Fig. 5c), then diverged from each other after the 1920s, when considering the entire G/B 1708-2008 period (Fig. 5c). Coherent temporal changes in signal timing and phase between both records showed that positive phases of the PDO corresponded to positive runoff anomalies (Fig. 5c). Comparing the filtered Shen et al. (2006) PDO reconstruction with the coral runoff record revealed similar changes in timing and phase for over two centuries in the multidecadal frequency band (Fig. 5c). However, again when considering the entire G/B 1708-2008 period the two records diverged from each other after the 1920s, similar to the D'Arrigo and Wilson (2006) record (Fig. 5c).

\subsection{Post-1920 climatic modulation of runoff}

To further investigate post-1920 PDO modulation of eastern Madagascar soil runoff, we also analysed the $\mathrm{G} / \mathrm{B}$ records of additional corals in combination with high resolution geochemistry. Together, they allowed us to decouple the three major components influencing eastern Madagascar soil runoff; i.e. human land use changes and natural decadal climate variability interacting with Indian Ocean warming. Long-term changes in runoff appear in the $11 \mathrm{yr}$ running mean of both $\mathrm{G} / \mathrm{B}$ and $\mathrm{Ba} / \mathrm{Ca}$ in each coral (MAS1, Fig. 6a, c; MAS3, Fig. 6d, f). An 11 yr running mean was applied to the data in order to remove high-frequency noise and highlight long-term trends (Fig. 6). Most pronounced is the continuous increase in humic acid runoff $(\mathrm{G} / \mathrm{B})$ since the mid-1970s and sediment runoff $(\mathrm{Ba} / \mathrm{Ca})$ from the mid-1950s. In recent years both proxies have increased to maximum values, seemingly in concert with rising south central Indian Ocean SST (Fig. 6).

The longest continuous precipitation record from Madagascar (Antananarivo) is also in agreement with the two coral $\mathrm{Ba} / \mathrm{Ca}$ records and the south central Indian Ocean SST dataset, whereby rainfall increased from the mid-1950s until the record ends in 1987 (Fig. 6b, e). Consequently, increasing $\mathrm{Ba} / \mathrm{Ca}$ appears tightly coupled to rising SST and precipitation (Fig. 6). However, unlike $\mathrm{Ba} / \mathrm{Ca}$, a reduced coherence between humic acid runoff $(\mathrm{G} / \mathrm{B})$ and Indian Ocean SST is observed in the mid-20th century (Fig. 6). This suggests that factors other than rainfall may be involved in the large-scale erosion of humic acids during this period. Discrepancies between G/B and SST occur in both cores analysed for geochemistry for the periods 1945-1955 and 19661980, whereby G/B increases while SST decreases (19401960) or remains stable (1960-1980). These periods are also marked by enhanced coral $\mathrm{Mn} / \mathrm{Ca}$ above the seasonal background (Figs. 6 and B1; Appendix B).

$\mathrm{Mn}$ is an indicator for biological activity in seawater (Abram et al., 2003; Wyndham et al., 2004). Fallon et al. (2002) and Alibert et al. (2003) proposed two possible mechanisms for the seasonal cycle in $\mathrm{Mn} / \mathrm{Ca}$. An increase in the photoreductive dissolution of suspended particulate Mn oxides, which increases in spring with increasing solar 

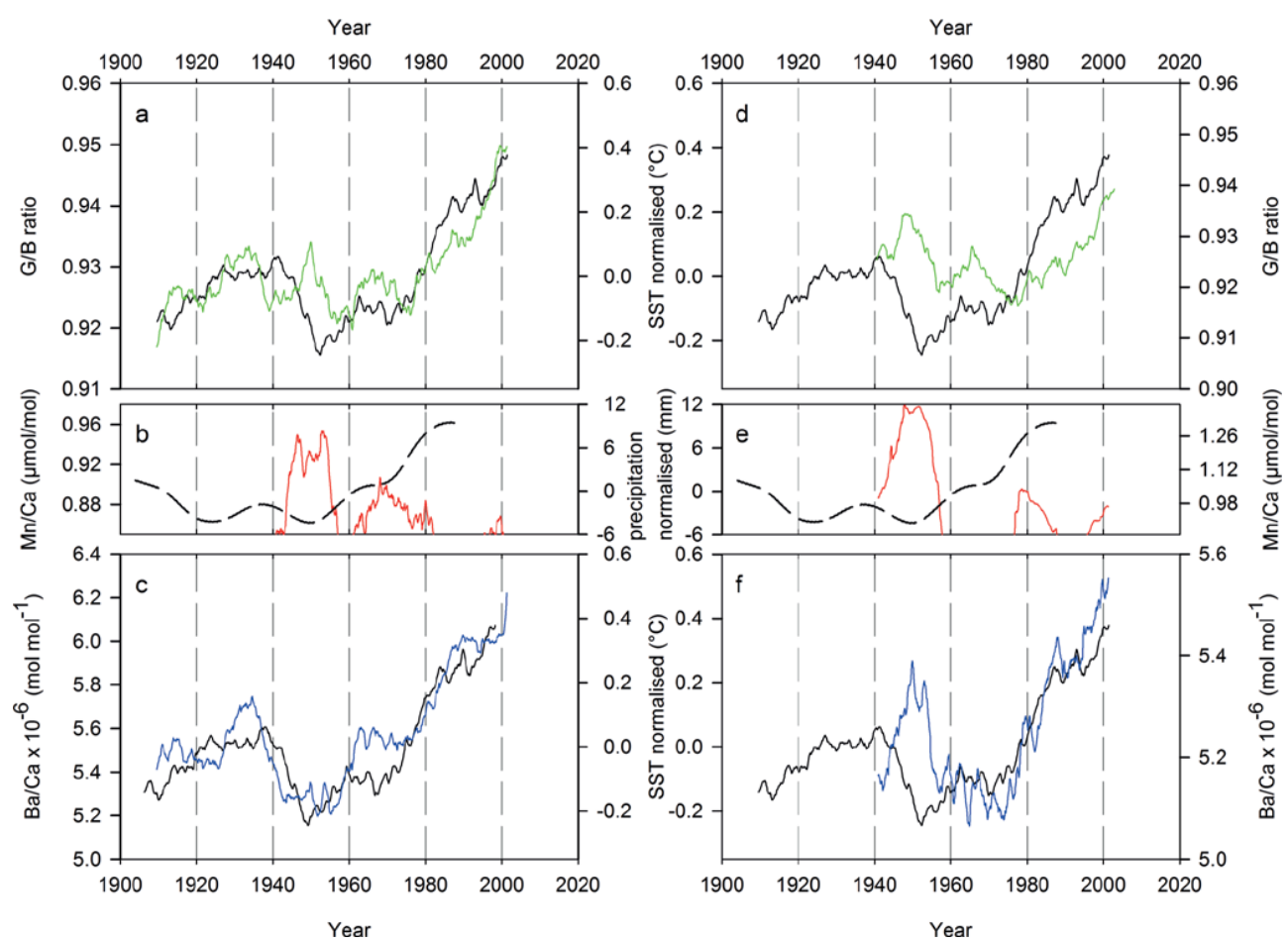

Fig. 6. An 11 yr running mean of MAS1 and MAS3 coral G/B (green) compared to the SST anomaly (ERSSTv.3) for the southern central Indian Ocean 5-20 $\mathrm{S}, 60-90^{\circ} \mathrm{E}$ (black) since 1904 (a, d), the coral Mn/Ca (red solid; $\mu \mathrm{mol} \mathrm{mol}{ }^{-1}$ ) (b, e), and the $\mathrm{Ba} / \mathrm{Ca}(\mathrm{blue})(\mathbf{c}, \mathbf{f})$. Note that multidecadal oscillations in $\mathrm{G} / \mathrm{B}$ and $\mathrm{Ba} / \mathrm{Ca}$ show high coherence with SST. Higher $\mathrm{Mn} / \mathrm{Ca}$ ratios identify periods of slash-and-burn deforestation that overprint the climatic control of humic acid runoff. Differences observed between $\mathrm{Ba} / \mathrm{Ca}$ and $\mathrm{G} / \mathrm{B}$ are linked to watershed composition. A 360-month low pass filter of Antananarivo precipitation anomalies $\left(18.80^{\circ} \mathrm{S}, 47.50^{\circ} \mathrm{E}, 1276 \mathrm{~m}\right.$, WMO station code: 67083 ANTANANARIVO/IVATO) is shown (black dashed; b, e), indicating increasing rainfall conditions until 1987. Note that this precipitation record ends in 1987 due to recent data gaps.

radiation (Fallon et al., 2002; Alibert et al., 2003); or alternatively, a diagenetic release of $\mathrm{Mn}$ at the seawater sediment interface as a result of reducing conditions induced by decaying organic matter produced in spring and summer (Alibert et al., 2003). The latter process is what we infer from the Mn spikes observed here, which we relate to intense deforestation periods (Abram et al., 2003; Wyndham et al., 2004).

High Mn levels are associated with decaying organic matter following ash fallout from wildfires, which promote phytoplankton blooms (red tides). As the organic matter decays with time it produces reducing conditions, subsequently increasing seawater Mn concentrations (Abram et al., 2003; Wyndham et al., 2004). Indeed, the pronounced increase in $\mathrm{Mn} / \mathrm{Ca}$ testifies to the well documented intense slash-andburn deforestation for upland rice cultivation between 1950 and 1980 (Green and Sussman, 1990; Harper et al., 2007), associated with the economic collapse of Madagascar and the return to subsistence agriculture. In the MAS1 and MAS3 records, G/B increases approximately at the same time as $\mathrm{Mn} / \mathrm{Ca}$ during this period, which is consistent with the massive addition of organic matter after the documented periods of high slash-and-burn deforestation (Green and Sussman, 1990; Harper et al., 2007). Segmentation analysis (Webster,
1973, 1980) of the coral composite G/B record (MAS1, MAS3, MASB and ANDRA) further highlights these mid20th century human deforestation periods, as well as climatic shifts associated with the IPO-PDO (Fig. C1; Appendix C; Supplement).

The coupling between increasing runoff and south central Indian Ocean warming is evident after the prominent climate shift around 1976/1977, when both global mean temperatures and runoff strongly increased (Fig. 6) (Meehl et al., 2009). As $\mathrm{Mn}$ is also associated with seasonal soil runoff through erosion (Lewis et al., 2007), we observe similar increasing linear trends in the $\mathrm{G} / \mathrm{B}$ and $\mathrm{Mn} / \mathrm{Ca}$ ratios (Fig. B1; Appendix B). Because G/B is a direct indicator of soil erosion and not rainfall, we attempted to remove the deforestation effect using the available coral geochemical records (MAS1 and MAS3; MAS1/3 composite), by subtracting the normalised MAS1/3 Mn/Ca composite record from the normalised MAS1/3 G/B composite record, prior to singular spectrum analysis (Figs. 7 and B1; Appendix B). This also removed the long-term erosion trend, resulting in a MAS1/3 $\mathrm{G} / \mathrm{B}-\mathrm{Mn} / \mathrm{Ca}$ composite record that reflects the natural rainfall variability, now increasing from the mid-1950s in agreement with the SST and $\mathrm{Ba} / \mathrm{Ca}$ data (Figs. 6 and 7). 


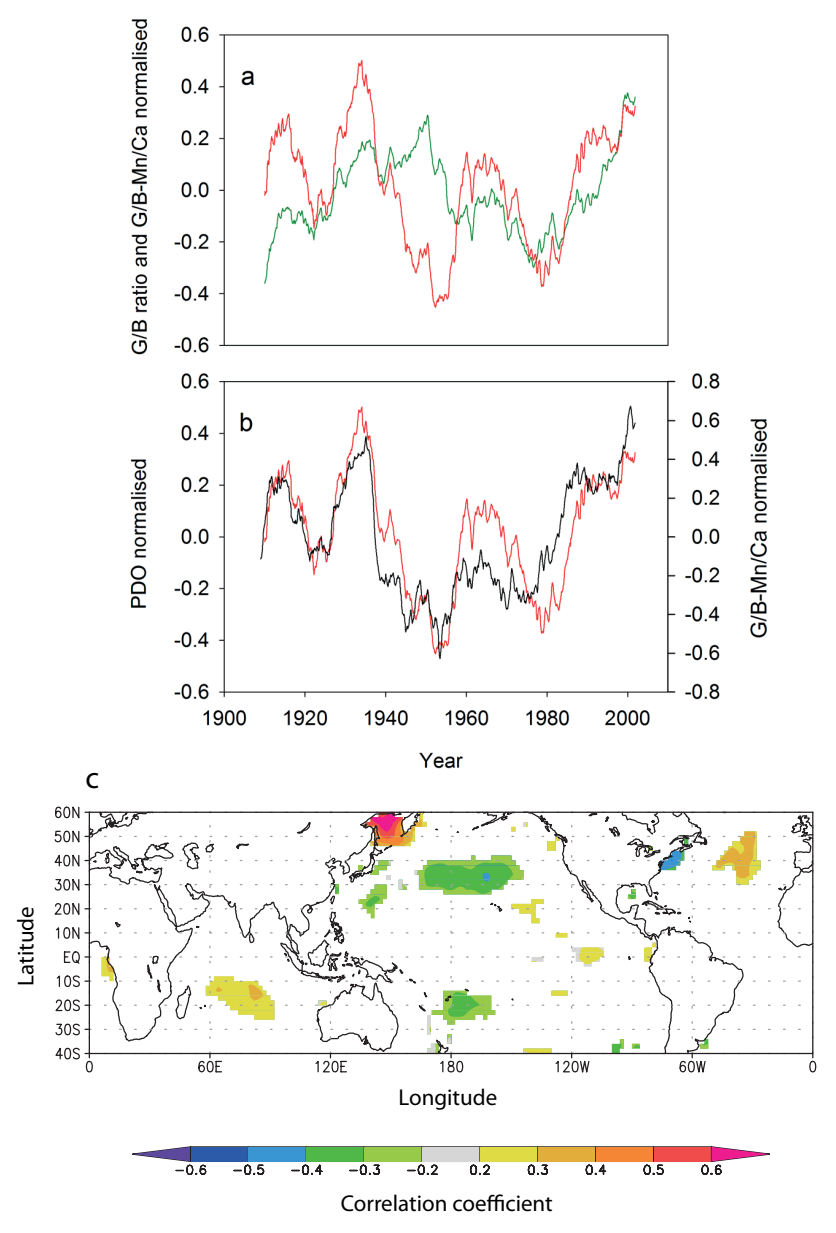

Fig. 7. The $11 \mathrm{yr}$ running means $(\mathbf{a}, \mathbf{b})$ of the normalised MAS $1 / 3$ (MAS1 and MAS3 combined; Appendix B) G/B composite record (green), normalised MAS1/3 G/B-Mn/Ca composite record (red) and the PDO (black). Note, with the removal of $\mathrm{Mn} / \mathrm{Ca}$ from the $\mathrm{G} / \mathrm{B}$ record, runoff is more in phase with the PDO. The spatial correlation of global SST (ERSSTv.3) with (c) the 360-month low pass filter of normalised MAS1/3 G/B-Mn/Ca composite indicates a PDO-like spatial SST patterns (Fig. 5a). Only correlations above $95 \%$ significance level are shown. Correlations were computed at http://climexp.knmi.nl/.

Spectral analysis of the monthly instrumental PDO index (1880-present) (Mantua et al., 1997) and coral MAS1/3 G/B$\mathrm{Mn} / \mathrm{Ca}$ composite show strong power in the interdecadal and multidecadal band (Fig. B2), which is in agreement with the pre-1920 frequency analysis of MASB G/B and the Asian based PDO indices (D'Arrigo and Wilson, 2006; Shen et al., 2006) (Figs. 3 and S3). The tight temporal relationship of the G/B-Mn/Ca composite time series with the PDO index shows that a positive (negative) phase is associated with wet (dry) conditions (Fig. 7). Interestingly, the G/B-Mn/Ca composite correlates with typical positive PDO-like conditions in global SSTs, coupled with a positive correlation with south central Indian Ocean SST (Figs. 7 and 8). Also, in the $\mathrm{Sr} / \mathrm{Ca}$

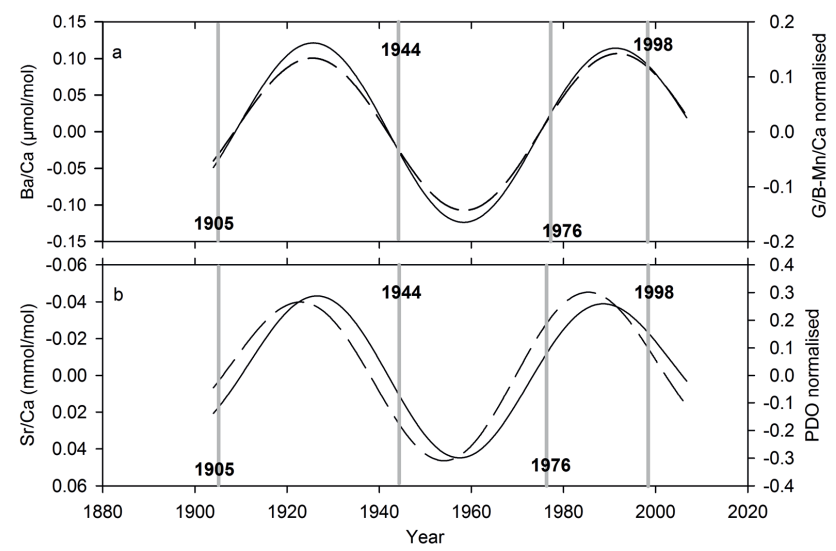

Fig. 8. A $50-70 \mathrm{yr}$ band pass filter $(0.017 \pm 0.003)$ applied to (a) MAS1 $\mathrm{Ba} / \mathrm{Ca}$ (dashed) and MAS1 G/B-Mn/Ca (solid); and (b) MAS1 Sr/Ca data (dashed) and the Mantua PDO index (solid). The grey bars represent the transition years of different phase changes of the PDO.

temperature proxy record of MAS1, a positive PDO phase is associated with a warm SST anomaly (Fig. 8), pointing to a typical SST pattern found in the Indian Ocean in response to Pacific decadal forcing (Krishnan and Sugi, 2003; Cole et al., 2000; Deser et al., 2004; Crueger et al., 2009). The temporal alignment of all records $(\mathrm{Sr} / \mathrm{Ca}, \mathrm{Ba} / \mathrm{Ca}, \mathrm{G} / \mathrm{B}-\mathrm{Mn} / \mathrm{Ca})$ with the PDO (Fig. 8) therefore argues for Pacific modulation of Madagascar river runoff and rainfall on multidecadal timescales for at least the past $300 \mathrm{yr}$.

\subsection{IPO-PDO climatic modulation of runoff}

Madagascar is an iconic example of the extreme environmental impacts human deforestation and habitat destruction has on soil runoff and land degradation (Green and Sussman, 1990; Harper et al., 2007). Human activity is also reported for two 200-300 yr erosion records from Kenya (Malindi), based on coral $\mathrm{Ba} / \mathrm{Ca}$, that show a simultaneous major shift in base level runoff at $1906 \pm 3 \mathrm{yr}$ and $1908 \pm 5 \mathrm{yr}$ (Fleitmann et al., 2007). This 1908 shift in soil erosion was attributed predominantly to a change from traditional subsistence agriculture to intensive European land use practices introduced by the British settlers. The Kenya coral records also indicate accelerated soil erosion between the late 1940s and early 1950s and in the late 1970s following periods of intense drought, which occur simultaneously with shifts in the Madagascar coral records presented here. Further, these multidecadal runoff changes co-occur with the 1905, 1947 and 1976 shifts in the PDO and IO SST, suggesting a possible link to Pacific modulation of Kenyan soil erosion by rainfall. For the same (Malindi) coral, SST was reconstructed using $\delta^{18} \mathrm{O}$ as a proxy (Cole et al., 2000). This was shown to be strongly linked with Pacific decadal SST variability and North Pacific SLP, supporting the importance of Pacific decadal forcing on western Indian Ocean climate (Cole et al., 

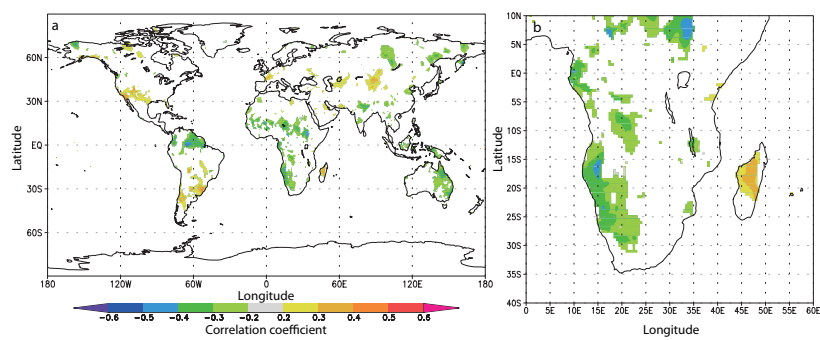

Fig. 9. Spatial correlation of mean annual averages (May to April) of the Pacific Decadal Oscillation (PDO) (Mantua et al., 1997) with global annually averaged (May to April) rainfall data produced by the Climate Research Unit (CRU) at the University of East Anglia (CRU TS3) (Mitchell and Jones, 2005). Correlations are shown over the globe (a) and for central and southern Africa (b). Colour shading represents confidence of $95 \%$ and greater. Red shading indicates positive correlations and green negative correlations. Note the positive correlation of rainfall with the PDO over Madagascar and negative correlation over eastern Australia and the northern Rocky Mountains, North America. Correlations were computed at http://climexp.knmi.nl/.

2000; Cobb et al., 2001; Deser et al., 2004; D'Arrigo et al., 2005).

The PDO/river runoff relationship in Great Barrier Reef corals and east Australia river gauges is opposite to that in Madagascar, as the negative PDO phase (i.e. 1947 to 1976) is linked with higher river discharge, and vice versa for the positive PDO phase (Lough, 2007; McGowan et al., 2009). Correlating precipitation with the principle component time series of the IPO (Meehl and Hu, 2006), and the PDO (Felis et al., 2010) shows a negative response over eastern Australia and southern Africa, and a positive response in eastern Madagascar and eastern Africa (Meehl and Hu, 2006; Felis et al., 2010). A spatial correlation of the PDO and global rainfall supports these results, with a negative correlation shown in southern Africa, eastern Australia (Lough, 2007; McGowan et al., 2009) and the northern Rocky Mountains (St. Jacques et al., 2010), as well as a positive correlation in Madagascar (Fig. 9). Since Indian Ocean SST is sensitive to the PDO (Krishnan and Sugi, 2003), and rainfall is linked to SST (Goddard and Graham, 1999), runoff variability is ultimately linked to Pacific Ocean decadal variability. During the positive IPO-PDO phases, higher mean SST is responsible for enhanced atmospheric convection over the Indian Ocean, which in turn drives anomalous subsidence over southern Africa and eastern Australia (Lough, 2007; Goddard and Graham, 1999; Richard et al., 2000; Hoerling et al., 2006; McGowan et al., 2009). The robust Indian Ocean SST signal associated with decadal Pacific SST and SLP variability is most likely responsible for shifting the hydrological balance in the Indian Ocean, which is detected in the $\mathrm{G} / \mathrm{B}$ and $\mathrm{Ba} / \mathrm{Ca}$ records from eastern Madagascar. However, the specific mechanisms responsible for such teleconnections are beyond the scope of this paper and require further investigation.
Clear differences are observed between the PDO reconstructions before the 20th century. Henley et al. (2011) ascribe these differences to a number of possible reasons, including (1) uncertainties associated with the paleo-data itself and its interpretation, (2) nonlinearities and errors in the original physical data analysis, (3) nonstationarity of the proxy/climate relationship, and/or (4) the different levels of explained variance between the various proxies at various locations. Schneider and Cornuelle (2005) suggest that perhaps the PDO is not itself a mode of variability but is a blend of three phenomena. Given instrumental records are too short to provide a robust assessment and paleoclimate records conflict regarding timescales (Biondi et al., 2001; Gedalof et al., 2002), we cannot rule out this possibility that no well-defined coupled ocean-atmosphere "mode" of variability exists in the Pacific on decadal to multidecadal timescales pre-1900. However, what is clear is that a strong teleconnected response does exist between eastern Asia and the southwest Indian Ocean on multidecadal and interdecadal timescales beyond the 1900s, likely driven by SST variability in the northern Pacific and southwestern Indian Ocean. The MASB coral luminescence record highlights this with its strong continuous coherence with the Asian PDO reconstructions.

The long-term coral data presented here suggest that southwest Indian Ocean rainfall is indirectly linked to $\mathrm{Pa}$ cific decadal variability, transmitted through the Asian Monsoon circulation. Consequently, for the upcoming decades, rainfall in eastern Madagascar is expected to decrease, as the PDO is currently in a transition from a positive to a negative phase. Elsewhere, IPO-PDO teleconnected regions with weaker rains in recent decades should experience more precipitation, i.e. in eastern Australia and southern Africa (Cai and van Rensch, 2012). It remains a major milestone in future research to unravel if and when projected anthropogenic warming of the Indian Ocean (Forster et al., 2007) will dominate rainfall over the inherent multidecadal component. The data presented here illustrate this interplay as an acceleration of rainfall and erosion following the prominent 1976/1977 climate shift (Meehl et al., 2009), which is related to both anthropogenic and multidecadal forcing. However, we cannot rule out that mid-century deforestation may have also enhanced the observed post-1976 acceleration in G/B (Maina et al., 2012).

\section{Appendix A}

\section{Coral luminescence and G/B}

Changing luminescent intensities observed in coral cores were originally thought to be caused by the skeletal incorporation of soil-derived humic acids (Isdale, 1984; Susic and Boto, 1989; Matthews et al., 1996; Isdale et al., 1998; Wild et al., 2000). Variability in coral skeletal density and architecture were later proposed as the cause since banded 


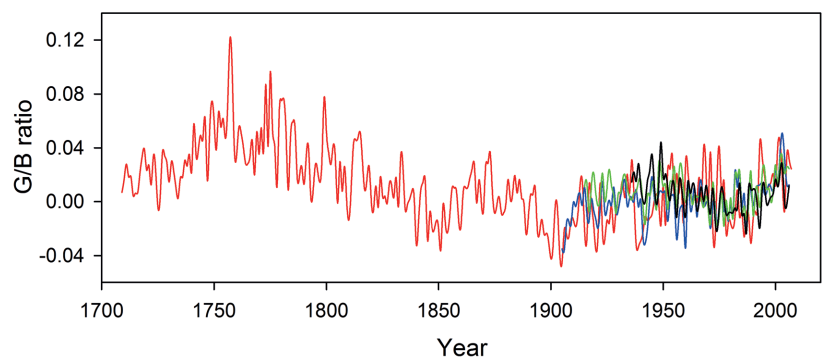

Fig. A1. Annual average G/B anomalies of MASB (red), MAS1 (blue), ANDRA (green) and MAS3 (black). Anomalies were calculated by subtracting the mean annual average G/B value for 19611990 (common period) from individual records. Correlations of records are shown in Table 1.

luminescence is also observed in corals far from terrestrial inputs (Barnes and Taylor, 2001, 2005). However, a combination of both humic acids and skeletal density/architecture likely explain the observed changing luminescent intensities in coral skeletons. To accurately reconstruct river runoff, deconvolution of the two fractions is required (Grove et al., 2010).

Spectral luminescence scanning (SLS) is an applied technique that separates the intensity of coral luminescence emissions into three spectral domains: red, green, and blue (RGB) (Grove et al., 2010). High-quality, normalised photoluminescence images are generated using SLS, which are composed of multiple RGB pixels with a linear resolution of $71.4 \mu \mathrm{m}$ (Grove et al., 2010). As the luminescent emission signals of humic acids (G) are slightly longer than aragonite (B), taking the green/blue $(\mathrm{G} / \mathrm{B})$ ratio identifies the amount of humic acids locked within the coral relative to the skeletal density (Grove et al., 2010). SLS resolves many density/architectural effects associated with luminescence intensities, such as declining trends in intensity with coral age (Jones et al., 2009; Lough, 2011a, b). For our study site of Antongil bay (NE Madagascar), relationships of G/B with runoff/precipitation have previously been formulated on comparisons with other runoff proxies (Grove et al., 2010, 2012), modelled river discharge data (Grove et al., 2012; Maina et al., 2012) and/or precipitation data from weather stations located hundreds of kilometres form the study site (Grove et al., 2010). Here, we show that $\mathrm{G} / \mathrm{B}$ is significantly correlated with four separate rainfall datasets for the Antongil region (Figs. A1 and A2), verifying the precipitation link with coral records. corr MAS COMP G/B with Mar-Feb averaged $\quad$ corr MAS COMP G/B with Jan-Dec averaged
CRU TS3.10.01 precipitation (detrend) 1939-2006 $\mathrm{p}<5 \%$ CMAP precipitation (detrend) $1979-2006 \mathrm{p}<5 \%$

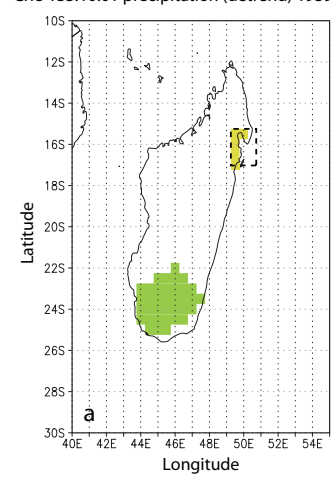

corr MAS COMP G/B with Mar-Feb averaged NCEP/NCAR precipitation (detrend) 1948-2006 $\mathrm{p}$

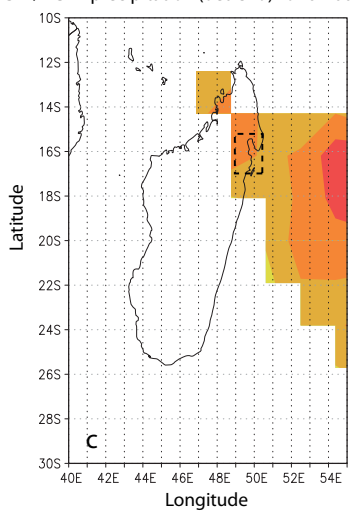

corr MAS COMP G/B with Jan-Dec averaged

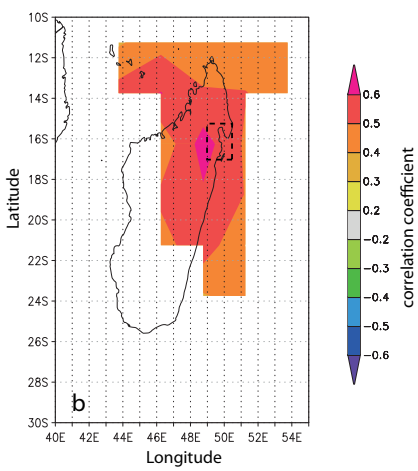
AMSOPI precipitation (detrend) $1979-2006 \mathrm{p}<5 \%$

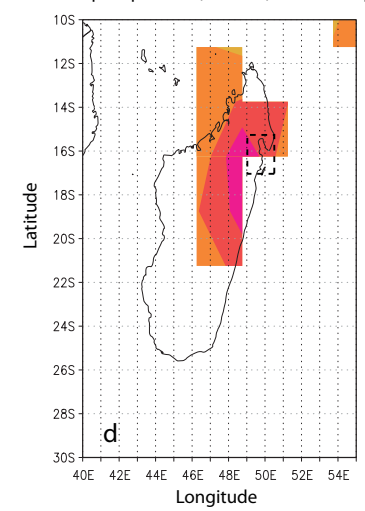
CMAP precipitation (detrend) 1979-2006 $\mathrm{p}<5 \%$

corr MAS COMP G/B with Jan-Dec averaged

Fig. A2. Spatial correlations of the annual mean MAS G/B composite record with rainfall data from (a) CRU TS3.10.01 (Mitchell and Jones, 2005), (b) CMAP (Xie and Arkin, 1997), (c) NCEP/NCAR reanalysis (Kalnay et al., 1996) and (d) CAMS_OPI (Janowiak and Xie, 1999). The mean annual average for the optimal correlation with the $\mathrm{G} / \mathrm{B}$ record has been chosen for individual rainfall datasets. The G/B composite record was composed of MAS1, MAS3, MASB and ANDRA for the common time period of 1930-2006. Only correlations $>95 \%$ significance level are shown in colour. See legend for correlation coefficients. Study area indicated by rectangular box (stipled). Correlations computed at http://climexp.knmi.nl/.

\section{Appendix B}

\section{Coral Mn/Ca}

The coral $\mathrm{Mn} / \mathrm{Ca}$ record is in and out of phase with the G/B time series on seasonal timescales, highlighted by MAS1 (Fig. B1). This implies that Mn concentrations, associated with slash-and-burn deforestation, increase in Antongil bay during both the wet and dry seasons. Both $\mathrm{G} / \mathrm{B}$ and $\mathrm{Mn} / \mathrm{Ca}$ also have similar linear trends (Fig. B1), indicating that a fraction of $\mathrm{Mn}$ is likely flushed into the bay associated with the soils or sediment (Lewis et al., 2007). To remove the deforestation induced erosion signal from the G/B records, we attempted a novel approach using the two coral records MAS1 and MAS3. As the normalised monthly $\mathrm{Mn} / \mathrm{Ca}$ and G/B records, for both MAS1 and MAS3, had identical 


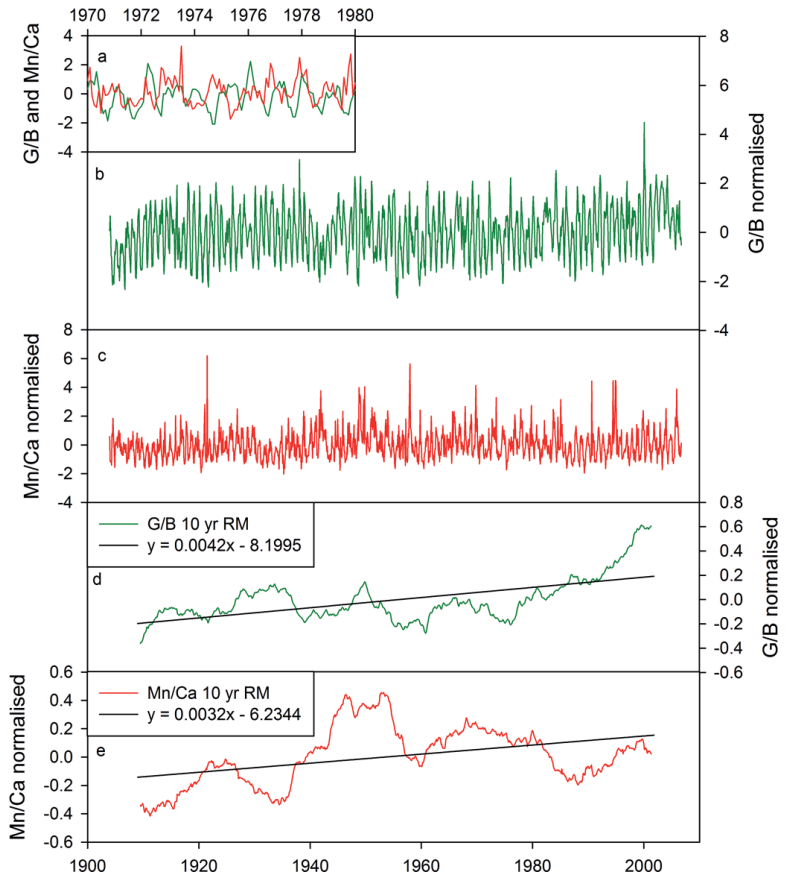

Fig. B1. The seasonal alignment of (a) the MAS1 coral G/B record with Mn/Ca values for the years 1970-1980. The complete MAS1 time series of normalised (b) $\mathrm{G} / \mathrm{B}$ and (c) $\mathrm{Mn} / \mathrm{Ca}$ is shown in green and red, respectively. The $11 \mathrm{yr}$ running means of (d) G/B and (e) $\mathrm{Mn} / \mathrm{Ca}$ are shown together with linear trends of monthly data (black line). The regression equations of each line are given in the top left hand corner of each plot. Note that the trend lines have a similar slope.
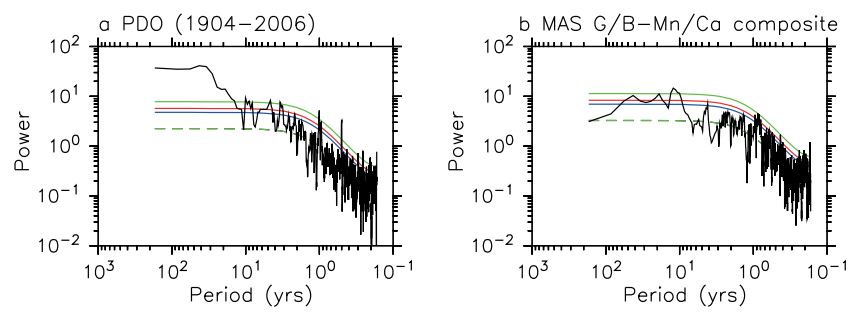

Fig. B2. Spectrum of (a) the PDO index (Mantua et al., 1997) and (b) the MAS1/3 G/B-Mn/Ca composite record. Monthly anomaly data from January 1904 to October 2006 are used, whereby the monthly climatology of 1904-2005 is removed. Confidence levels are indicated with green (99\%), red (95\%), blue (90\%) and green dashed (median) lines, respectively.

standard deviation values of 1.0, for the same period, we created a composite $\mathrm{G} / \mathrm{B}$ and composite $\mathrm{Mn} / \mathrm{Ca}$ record based on the two corals (MAS1/3). Records were normalised by subtracting the mean and dividing by the standard deviation. By subtracting the normalised $\mathrm{Mn} / \mathrm{Ca}$ composite record from the normalised $\mathrm{G} / \mathrm{B}$ composite record, we removed the deforestation effect, as well as the long-term runoff trend (Fig. B1), leaving a G/B-Mn/Ca record that primarily shows the natural runoff variability (Figs. 7 and B2).
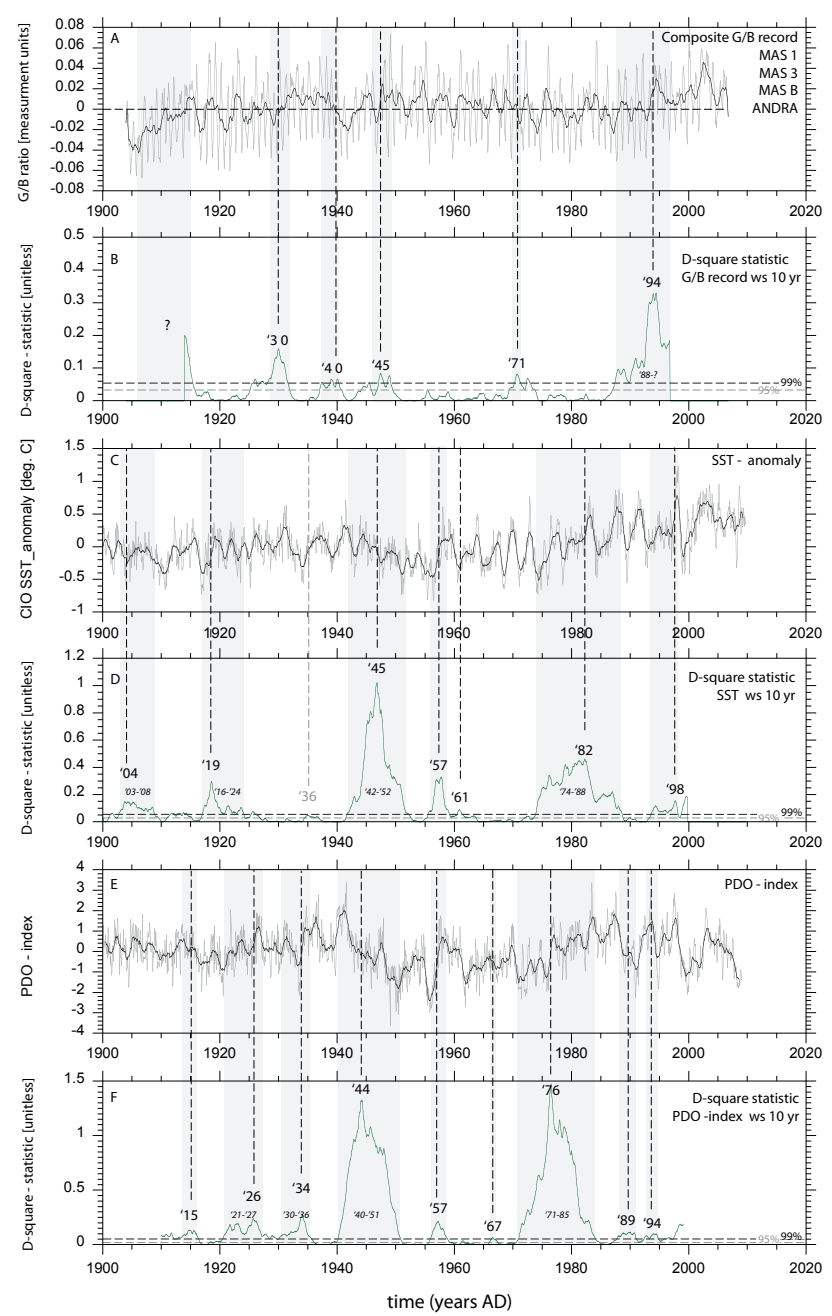

Fig. C1. Record segmentation of the 4 core composite G/B record (MASB, MAS1, MAS3 and ANDRA), PDO index and south CIO ERSST (Smith et al., 2008). (A) shows the raw G/B composite record with a 13 point smoothing superimposed, $(\mathbf{C})$ the south $\mathrm{CIO}$ ERSST data with a 13 point smoothing superimposed, and (E) the raw PDO time series with a 13 point smoothing superimposed. The change points (green) which are above the $99 \%$ (black dashed) and $95 \%$ (grey dashed) significance level are shown for G/B (B), the PDO index (D) and south CIO ERSST (F). Major change points are indicated by years and transition periods by grey bands. The first and last $10 \mathrm{yr}$ cannot be used for interpretation.

\section{Appendix C}

\section{Record segmentation analysis}

Record segmentation analysis of the coral composite G/B record, which includes MASB, MAS1, MAS3 and ANDRA (Fig. 1), identify years within the G/B time series that correspond to phase changes in the PDO and south central Indian Ocean SST (CI SST) (Fig. C1; Supplement). Two major shifts are detected in the PDO time series: between 1940 and 
1951, towards a negative index, and between 1971 and 1985, towards a positive index. The timing of these major shifts is in agreement with PDO multidecadal changes as described in previous studies (Minobe, 1997; Mantua et al., 1997). The 1940-1951 shift of the PDO is associated with a shift in the composite G/B record and SST data (Fig. C1). The SST data, however, show a pronounced transition to cooler SST between 1942 and 1952, hence approx. 1-2 yr after the shift in the PDO (Fig. C2). This is most likely an artefact created by the sampling bias in observational data for this period (Gedalof et al., 2002). At the second major shift in the PDO between 1971 and 1985, the south central Indian Ocean SST show a transition from 1974 to 1988, whereas $\mathrm{G} / \mathrm{B}$ does not record this transition, with the exception of a weak signal cantered at 1971 (Fig. C1). This is likely explained by a perturbation created by the 1970s deforestation period. In general, all transitions in G/B between 1950 and 1980 are moderate (e.g. in 1956), most likely caused by the enhanced deforestation period, which is marked by the highly pronounced $\mathrm{Mn} / \mathrm{Ca}$ peaks (Figs. 4 and B1). Nevertheless, significant shifts $(2 \times 10-\mathrm{yr}$ window $)$ in the G/B did occur in 1930, 1940, 1945, 1971, and 1994 (Fig. C1a). The 1994 shift most likely marks the start of a transition to a negative PDO phase on multidecadal timescales (Verdon and Franks, 2006). Minor shifts in the PDO are associated with the interdecadal frequency mode (Interdecadal Pacific Oscillation/IPO) (Fig. C1).

\section{Supplementary material related to this article is available online at: http://www.clim-past.net/9/641/2013/ cp-9-641-2013-supplement.pdf.}

Acknowledgements. This work was supported as part of the SINDOCOM grant under the Dutch NWO program "Climate Variability", grant 854.00034/035. Additional support comes from the NWO ALW project CLIMATCH, grant 820.01.009, and the Western Indian Ocean Marine Science Association through the Marine Science for Management programme under grant MASMA/CC/2010/02. We thank the Wildlife Conservation Society (WCS) Madagascar, especially Heriliala Randriamahazo and the WCS/ANGAP team in Maroantsetra, for their support in fieldwork logistics and in the organisation of the research permits. We would also like to thank CAF/CORE Madagascar for granting the CITES permit and ANGAP Madagascar for support of our research activities in the vicinity of the marine and forest nature parks. Furthermore, we would like to thank Bob Koster and Rineke Gieles for their continuous development and maintenance of the XRF-Core Scanner, and Rik Tjallingii and Thomas Richter for their fruitful discussions concerning the manuscript. We are grateful to the ARC Centre of Excellence in Coral Reef Studies and ANU Research School of Earth Sciences for support of the Laser-Ablation analysis. JZ was supported by a collaborative UWA/AIMS/CSIRO postdoctoral fellowship.

Edited by: N. Abram

\section{References}

Abram, N. J., Gagan, M. K., McCulloch, M. T., Chappell, J., and Hantoro, W. S.: Coral reef death during the 1997 Indian Ocean Dipole linked to Indonesian wildfires, Science, 301, 952-955, 2003.

Alibert, C. and McCulloch, M. T.: Strontium/calcium ratios in modern Porites corals from the Great Barrier Reef as a proxy for sea surface temperature: calibration of the thermometer and monitoring of ENSO, Paleoceanography, 12, 345-363, 1997.

Alibert, C., Kinsley, L., Fallon, S. J., McCulloch, M. T., Berkelmans, R., and McAllister, F.: Source of trace element variability in Great Barrier Reef corals afected by the Burdekin flood plumes, Geochim. Cosmochim. Ac., 67, 231-246, 2003.

Arblaster, J. M., Meehl, G. A., and Moore, A.: Interdecadal modulation of Australian rainfall, Clim. Dynam., 18, 519-531, 2002.

Barnes, D. J. and Taylor, R. B.: On the nature and causes of luminescent lines and bands in coral skeletons, Coral Reefs, 19, 221-230, 2001.

Barnes, D. J. and Taylor, R. B.: On the nature and causes of luminescent lines and bands in coral skeletons: II. Contribution of skeletal crystals, J. Exp. Mar. Biol. Ecol., 322, 135-142, 2005.

Beck, J. W., Edwards, R. L., Ito, E., Taylor, F. W., Recy, J., Rougerie, F., Joannot, and P., Henin, C.: Sea-surface temperatures from coral skeletal strontium/calcium ratios, Science, 257 , 644-647, 1992.

Biondi, F., Gershunov, A., and Cayan, D. R.: North Pacific Decadal Climate Variability since 1661, J. Climate, 14, 5-10, 2001.

Birkinshaw, C. and Randrianjanahary, M.: The effects of Cyclone Hudah on the forest of Masoala Peninsula, Madagascar, Madagascar Conservation \& Development, 2, 17-20, 2007.

Cai, W. and van Rensch, P.: The 2011 southeast Queensland extreme summer rainfall: A confirmation of a negative Pacific Decadal Oscillation phase?, Geophys. Res. Lett., 39, L08702, doi:10.1029/2011GL050820, 2012.

Cane, M. A.: Decadal predictions in demand, Nat. Geosci., 3, 231232, 2010.

Cole, J. E., Dunbar, R. B., McClanahan, T. R., and Muthiga, N. A.: Tropical Pacific forcing of decadal SST variability in the Western Indian Ocean over the past two centuries, Science, 287, 617-619, 2000.

Cobb, K. M., Charles, C. D., and Hunter, D. E.: A central tropical pacific coral demonstrates pacific, Indian, and Atlantic decadal climate connections, Geophys. Res. Lett., 28, 2209-2212, 2001.

Corrège, T.: Sea surface temperature and salinity reconstructions from coral geochemical tracers, Palaeogeogr. Palaeocl., 232, 408-428, 2006.

Crueger, T., Zinke, J., and Pfeiffer, M.: Patterns of Pacific decadal variability recorded by Indian Ocean corals, Int. J. Earth Sci., 98, 41-52, 2009.

D'Arrigo, R. and Wilson, R.: On the Asian expression of the PDO, Int. J. Climatol., 26, 1607-1617, 2006.

D'Arrigo, R., Villalba, R., and Wiles, G.: Tree-ring estimates of Pacific decadal climate variability, Clim. Dynam., 18, 219- 224, 2001.

D’Arrigo, R., Wilson, R., Deser, C., Wiles, G., Cook, E., Villalba, R., Tudhope, A., Cole, J., and Linsley, B.: Tropical-North Pacific climate linkages over the past four centuries, J. Climate, 18, 5253-5265, 2005. 
Deser, C., Phillips, A. S., and Hurrell, J. W.: Pacific Interdecadal climate variability: linkages between the tropics and the North Pacific during boreal winter since 1900, J. Climate, 17, 31093124, 2004.

Di Lorenzo, E., Schneider, N., Cobb, K. M., Franks, P. J. S., Chhak, K., Miller, A. J., McWilliams, J. C., Bograd, S. J., Arango, H., Curchitser, E., Powell, T. M., and Riviere, T.: North Pacific Gyre Oscillation links ocean climate and ecosystem change, Geophys. Res. Lett., 35, L08607, doi:10.1029/2007GL032838, 2008.

Fallon, S. J., McCulloch, M. T., van Woesik, R., and Sinclair, D.: Corals at their latitudinal limits: Laser ablation trace element systematic in Porites from Shirigai Bay, Japan, Earth Planet. Sc. Lett., 172, 221-238, 1999.

Fallon, S. J., White, J. C., and Mcculloch, M. T.: Porites corals as recorders of mining and environmental impacts: Misima Island, Papua New Guinea, Geochim. Cosmochim. Ac., 66, 45-62, 2002.

Felis, T., Suzuki, A., Kuhnert, H., Rimbu, N., and Kawahata, H.: Pacific Decadal Oscillation documented in a coral record of North Pacific winter temperature since 1873, Geophys. Res. Lett., 37, L14605, doi:10.1029/2010GL043572, 2010.

Fleitmann, D., Dunbar, R. B, McCulloch, M. T., Mudelsee, M., Vuille, M., McClanahan, T. R., Cole, J. E., and Eggins, S.: East African soil erosion recorded in a 300 year old coral colony from Kenya, Geophys. Res. Lett., 34, L04401, doi:10.1029/2006GL028525, 2007.

Forster, P., Ramaswamy, V., Artaxo, P., Berntsen, T., Betts, R., Fahey, D. W., Haywood, J., Lean, J., Lowe, D. C., Myhre, G., Nganga, J., Prinn, R., Raga, G., Schulz, M., and Van Dorland, R.: Changes in Atmospheric Constituents and in Radiative Forcing, Ch. 2 Climate Change 2007: The Physical Science Basis. Contribution of Working Group I to the Fourth Assessment Report of the Intergovernmental Panel on Climate Change, edited by: Solomon, S., Qin, D., Manning, M., Chen, Z., Marquis, M., Averyt, K. B., Tignor, M., and Miller, H. L., Cambridge Univ. Press, Cambridge, UK, 2007.

Funk, C., Dettinger, M. D., Michaelsen, J. C., Verdin, J. P., Brown, M. E., Barlow, M., and Hoell, A.: Warming of the Indian Ocean threatens eastern and southern African food security but could be mitigated by agricultural development, P. Natl. Acad. Sci., 105, 11081-11086, 2008.

Gedalof, Z. and Smith, D. J.: Interdecadal climate variability and regime-scale shifts in Pacific North America, Geophys. Res. Lett., 28, 1515-1518, 2001.

Gedalof, Z., Mantua, N. J., and Peterson, D. L.: A multi-century perspective of variability in the Pacific Decadal Oscillation: new insights from tree rings and coral, Geophys. Res. Lett., 29, 2204, doi:10.1029/2002GL015824, 2002.

Gerten, D., Rost, S., von Bloh, W., and Lucht, W.: Causes of change in 20th century global river discharge, Geophys. Res. Lett., 35, L20405, doi:10.1029/2008GL035258, 2008.

Ghil, M., Allen, R. M., Dettinger, M. D., Ide, K., Kondrashov, D., Mann, M. E., Robertson, A., Saunders, A., Tian, Y., Varadi, F., and Yiou, P.: Advanced spectral methods for climatic time series, Rev. Geophys., 40, 3.1-3.41, 10.1029/2000RG000092, 2002.

Goddard, L. and Graham, N. E.: Importance of the Indian Ocean for simulating rainfall anomalies over eastern and southern Africa, J. Geophys. Res., 104, 19099-19116, 1999.
Green, G. M. and Sussman, R. W.: Deforestation history of the eastern rain forests of Madagascar from satellite images, Science, 248, 212-215, 1990.

Grinsted, A., Moore, J. C., and Jevrejeva, S.: Application of the cross wavelet transform and wavelet coherence to geophysical time series, Nonlinear Proc. Geoph., 11, 561-566, 2004.

Grove, C. A., Nagtegaal R., Zinke, J., Scheufen, T., Koster, B., Kasper, S., McCulloch, M. T., van den Bergh, G., and Brummer, G.-J. A.: River runoff reconstructions from novel spectral luminescence scanning of massive coral skeletons, Coral Reefs, 29, 579-591, 2010.

Grove, C. A., Zinke, J., Scheufen, T., Maina, J., Epping, E., Boer, W., Randriamanantsoa, B., and Brummer, G.-J. A.: Spatial linkages between coral proxies of terrestrial runoff across a large embayment in Madagascar, Biogeosciences, 9, 3063-3081, doi:10.5194/bg-9-3063-2012, 2012.

Harper, G. J., Steininger, M. K., Tucker, C. J., Juhn, D., and Hawkins, F.: Fifty years of deforestation and forest fragmentation in Madagascar, Environ. Conserv., 34, 325-333, 2007.

Helmle, K. P., Dodge, R. E., Swart, P. K., Gledhill, D. K., and Eakin, C. M.: Growth rates of Florida corals from 1937 to 1996 and their response to climate change, Nat. Commun., 2, 215, doi:10.1038/ncomms1222, 2011.

Hendy, E. J., Gagan, M. K., and Lough, J. M.: Chronological control of coral records using luminescent lines and evidence for non-stationary ENSO teleconnections in northeast Australia, Holocene, 13, 187-199, 2003.

Henley, B. J., Thyer, M. A., Kuczera, G., and Franks S. W.: Climate informed stochastic hydrological modeling: Incorporating decadal-scale variability using paleo data, Water Resour. Res., 47, W11509, doi:10.1029/2010WR010034, 2011.

Hoerling, M., Hurrell, J., Eischaid, J., and Phillips, A.: Detection and attribution of 20th century northern and southern African rainfall change, J. Climate, 19, 3989-4008, 2006.

Isdale, P. J.: Fluorescent bands in massive corals record centuries of coastal rainfall, Nature, 310, 578-579, 1984.

Isdale, P. J., Stewart, B. J., Tickle, K. S., and Lough, J. M.: Palaeohydrological variations in a tropical river catchment: a reconstruction using fluorescent bands in corals of the Great Barrier Reef, Australia, Holocene, 8, 1-8, 1998.

Janowiak, J. E. and Xie, P.: CAMS_OPI: A Global Satellite-Rain Gauge Merged Product for Real-Time Precipitation Monitoring Applications, J. Climate, 12, 3335-3342, 1999.

Jones, P. D., Briffa, K. R., Osborn, T. J., Lough, J. M., van Ommen, T. D., Vinther, B. M., Luterbacher, J., Wahl, E. R., Zwiers, F. W., Mann, M. E., Schmidt, G. A., Ammann, C. M., Buckley, B. M., Cobb, K. M., Esper, J., Goose, H., Graham, N., Jansen, E., Kiefer, T., Kull, C., Kuttel, M., Mosley-Thompson, E., Overpeck, J. T., Riedwyl, N., Schulz, M., Tudhope, A. W., Villalba, R., Wanner, H., Wolff, E., and Xoplaki, E.: High-resolution paleoclimatology of the last millennium: a review of current status and future prospects, Holocene, 19, 3-49, 2009.

Jury, M. R., Parker, B. A., Raholijao, N., and Nassor, A.: Variability of summer rainfall over Madagascar: Climate determinants at interannual scales, Int. J. Climatol., 15, 1323-1332, 1995.

Kalnay, E., Kanamitsu, M., Kistler, R., Collins, W., Deaven, D., Gandin, L., Iredell, M., Saha, S., White, G., Woollen, J., Zhu, Y., Chelliah, M., Ebisuzaki, W., Higgins, W., Janowiak, J., Mo, K. C., Ropelewski, C., Wang, J., Leetmaa, A., Reynolds, R., Jenne, 
R. and Joseph, D.: The NCEP/NCAR 40-year reanalysis project, B. Am. Meteorol. Soc., 77, 437-470, 1996.

Kiem, A. S. and Franks, S. W.: Multi-decadal variability of drought risk - Eastern Australia, Hydrol. Process., 18, 2039-2050, 2004.

Kiem, A. S., Franks, S. W., and Kuczera, G.: Multi-decadal variability of flood risk, Geophys. Res. Lett., 30, 1035, doi:10.1029/2002GL015992, 2003.

Kremen, C.: The Masoala Peninsula, in: The Natural History of Madagascar: the Masoala Peninsula, edited by: Goodman, S. M. and Benstead J. P., University of Chicago Press, Chicago, 14591466, 2003.

Krishnan, P. and Sugi, M.: Pacific decadal Oscillation and variability of the Indian summer monsoon rainfall, Clim. Dynam., 21, 233-242, 2003.

Lewis, S. L., Shields, G. A., Kamber, B. S., and Lough, J. M.: A multi-trace element coral record of land-use changes in the Burdekin River catchment, NE Australia, Palaeogeogr. Palaeocl., 246, 471-487, 2007.

Lough, J. M.: Tropical river flow and rainfall reconstructions from coral luminescence: Great Barrier Reef, Australia, Paleoceanography, 22, PA2218, doi:10.1029/2006PA001377, 2007.

Lough, J., M.: Great Barrier Reef coral luminescence reveals rainfall variability over northeastern Australia since the 17th century, Paleoceanography, 26, PA2201, doi:10.1029/2010PA002050, 2011a.

Lough, J. M.: Measured coral luminescence as a freshwater proxy: comparison with visual indices and a potential age artefact, Coral Reefs, 30, 169-182, 2011b.

MacDonald, G. M. and Case, R. A.: Variations in the Pacific Decadal Oscillation over the past millennium, Geophys. Res. Lett., 32, L08703, doi:10.1029/2005GL022478, 2005.

Maina, J., de Moel, H., Vermaat, J. E., Bruggemann, H., Guillaume, M. M. M., Grove, C. A., Madin, J. S., Mertz-Kraus, R., and Zinke, J.: Linking coral river runoff proxies with climate variability, hydrology and land-use in Madagascar catchments, Mar. Pollut. Bull., 64, 2047-2059, doi:10.1016/j.marpolbul.2012.06.027, 2012.

Mann, M. E., Zhang, Z. H., Rutherford, S., Bradley, R. S., Hughes, M. K., Shindell, D., Ammann, C., Faluvegi, G., and Ni, F. B.: Global Signatures and Dynamical Origins of the Little Ice Age and Medieval Climate Anomaly, Science, 326, 1256-1260, 2009.

Mantua, N. J., Hare, S. R., Zhang, Y., Wallace, J. M., and Francis, R. C.: A Pacific interdecadal climate oscillation with impacts on salmon production, B. Am. Meteorol. Soc., 78, 1069-1079, 1997.

Matthews, B. J. H., Jones, A. C., Theodorou, N. K., Tudhope, A. W.: Excitation-emission-matrix fleorescence spectroscopy applied to humic acid bands in coral reefs, Mar. Chem., 55, 317-332, 1996.

McCulloch, M. T., Fallon, S., Wyndham, T., Hendy, E., Lough, J., and Barnes, D.: Coral record of increased sediment flux to the inner Great Barrier Reef since European settlement, Nature, 421, 727-730, 2003.

McGowan, H. A., Marx, S. K., Denholm, J., Soderholm, J., and Kamber, B. S.: Reconstructing annual inflows to the headwater catchments of the Murray River, Australia, using the Pacific Decadal Oscillation, Geophys. Res. Lett., 36, L06707, doi:10.1029/2008GL037049, 2009.

Meehl, G. A. and Hu, A.: Megadroughts in the Indian Monsoon Region and Southwest North America and a mechanism for associ- ated Multidecadal Pacific Sea Surface Temperature Anomalies, J. Climate, 19, 1605-1623, 2006.

Meehl, G. A., Hu, A., and Santer, B. D.: The mid-1970s climate shift in the pacific and the relative roles of forced versus inherent decadal variability, J. Climate, 22, 780-792, 2009.

Meinke, H., deVoil, P., Hammer, G. L., Power, S., Allan, R., Stone, R. C., Folland, C., and Potgieter, A.: Rainfall Variability at Decadal and Longer Time Scales: Signal or Noise?, J. Climate, 18, 89-96, 2005.

Minobe, S.: A 50-70 year climatic oscillation over the North Pacific and North America, Geophys. Res. Lett., 24, 683-686, doi:10.1029/97GL00504, 1997.

Mitchell, T. D. and Jones, P. D.: An improved method of constructing a database of monthly climate observations and associated high-resolution grids, Int. J. Climatol., 25, 693-712, doi:10.1002/joc.1181, 2005.

Nagtegaal, R., Grove, C. A., Kasper, S., Zinke, J., Boer, W., and Brummer, G.-J. A.: Spectral luminescence and geochemistry of coral aragonite: Effects of whole-core treatment, Chem. Geol., 318-319, 6-15, 2012.

Paillard, D., Labeyrie, L., and Yiou, P.: Macintosh program performs time series analysis, EOS T. Am. Geophys. Un., 77, 379379, 1996.

Power, S., Casey, T., Folland, C., Colman, A., and Mehta V.: Interdecadal modulation of the impact of ENSO on Australia, Clim. Dynam., 15, 319-324, 1999.

Reason, C. J. C. and Rouault, M.: ENSO-like decadal variability and South African rainfall, Geophys. Res. Lett., 29, 1638-1641, doi:10.1029/2002GL014663, 2002.

Richard, Y., Trzaska, S., Roucou, P., and Rouault, M.: Modification of the southern African rainfall variability/ENSO relationship since the late 1960's, Clim. Dynam., 16, 883-895, 2000.

Schneider, N. and Cornuelle, B. D.: The Forcing of the Pacific Decadal Oscillation, J. Climate, 18, 4355-4373, 2005.

Sinclair, D. J. and Mcculloch, M. T.: Corals record low mobile barium concentrations in the Burdekin River during the 1974 flood: evidence for limited Ba supply to rivers?, Palaeogeogr. Palaeocl., 214, 155-174, 2004.

Sinclair, D. J., Kinsley, L. P. J., and Mcculloch, M. T.: High resolution analysis of trace elements in corals by laser ablation ICPMS, Geochim. Cosmochim. Ac., 62, 1889-1901, 1998.

Shen, C., Wang, W.-C., Gong, W., and Hao, Z.: A Pacific Decadal Oscillation record since $1470 \mathrm{AD}$ reconstructed from proxy data of summer rainfall over eastern China, Geophys. Res. Lett., 33, L03702, doi:10.1029/2005GL024804, 2006.

Smith, T. M., Reynolds, R. W., Peterson, T. C., and Lawrimore, J.: Improvements to NOAA's Historical Merged Land-Ocean Surface Temperature Analysis (1880-2006), J. Climate, 21, 2283 2296, 2008.

St. Jacques, J.-M., Sauchyn, D. J., and Zhao, Y.: Northern Rocky Mountain streamflow records: Global warming trends, human impacts or natural variability? Geophys. Res. Lett. 37, L06407, doi:10.1029/2009GL042045, 2010.

Susic, M. and Boto, K. G.: High-performance liquidchromatographic determination of humic-acid in environmentalsamples at the nanogram level using fluorescence detection, J. Chromatogr., 482, 175-187, 1989.

Susic, M., Boto, K. G., and Isdale, P.: Fluorescent humic acid bands in coral skeletons originate from terrestrial runoff, Mar. Chem., 
33, 91-104, 1991.

Verdon, D. C. and Franks S. W.: Long-term behaviour of ENSO: Interactions with the PDO over the past 400 years inferred from paleoclimate records, Geophys. Res. Lett., 33, L06712, doi:10.1029/2005GL025052, 2006.

Verdon, D. C., Wyatt, A. M., Kiem, A. S., and Franks, S. W.: Multidecadal variability of rainfall and streamflow - Eastern Australia, Water Resour. Res., 40, W10201, doi:10.1029/2004WR003234, 2004.

Webster, R.: Automatic Soil-Boundary Location from Transect Data, Math. Geol., 5, 27-37, 1973.

Webster, R.: Divide: A FORTRAN IV program for segmenting multivariate one-dimensional spatial series, Comput. Geosci., 6, 6168, 1980.

Wild, F. J., Jones, A. C., and Tudhope, A. W.: Investigation of luminescence banding in solid coral: the contribution of phosphorescence, Coral Reefs, 19, 132-140, 2000.
Wyndham, T., McCulloch, M., Fallon, S., and Alibert, C.: Highresolution coral records of rare earth elements in coastal seawater: biogeochemical cycling and a new environmental proxy, Geochim. Cosmochim. Ac., 68, 2067-2080, 2004.

Xie, P. and Arkin, P. A.: Global precipitation: a 17-year monthly analysis based on gauge observations, satellite estimates, and numerical model outputs, B. Am. Meteorol. Soc., 78, 2539-2558, 1997.

Zinke, J., Pfeiffer, M., Timm, O., Dullo, W.-C., Kroon, D., and Thomassin, B. A.: Mayotte coral reveals hydrological changes in the western Indian Ocean between 1881 and 1994, Geophys. Res. Lett., 35, L23707, doi:10.1029/2008GL035634, 2008. 